\title{
Jean-Baptiste Fuzier: del vómito negro al arte precolombino
}

\section{Jean-Baptiste Fuzier: \\ From Black Vomit to Precolumbian Art}

Artículo recibido el 22 de septiembre de 20I8; devuelto para revisión el 25 de febrero de 20I9; aceptado el 20 de marzo de 2019; http://dx.doi.org/I0.2220I/iie.18703062e.2020.116.2717

Rosario Acosta Nieva Investigadora independiente, París. rosarioacosta20oı@yahoo.fr; http://orcid.org/oooo-oooI-7780-60oo

Líneas de investigación Antropología biológica; arqueología funeraria; literatura; historia de México.

Lines of research Biological anthropology; funerary archaeology; literature; Mexican history.

Publicación más relevante L'Ensemble funéraire du site de Caseta, Jalisco, Mexique: une approche archéo-anthropologique, Paris Monographs in American Archaeology I3, BAR-IS II97 (Oxford: Archaeopress, 2003).

Eric Taladoire Universidad de París I. Miembro de la uMR 8096, Arqueología de las Américas, CNRs, París. taladoire@yahoo.fr; erictaladoire@univ-parisı.fr, https://orcid.org/00oo-0002-5464-566X

Líneas de investigación Juego de pelota mesoamericano; historia de la arqueología; protección del patrimonio; historia de México.

Lines of research Mesoamerican ballgame; history of archaeological research; patrimony; Mexican history.

Publicación más relevante "Las aportaciones de los manuscritos pictográficos al estudio del juego de pelota", Anales del Instituto de Investigaciones Estéticas XXXVII, núm. IO6 (2015): I8I-22I.

Resumen Durante la guerra de Intervención en I862-I867, el doctor Fuzier, director del hospital militar francés de Veracruz, aprovechó su tiempo libre para excavar y dibujar una cantidad importante de piezas arqueológicas, desde vestigios mayores como la cabeza olmeca de Tres Zapotes, 
hasta figurillas y restos óseos. El manuscrito que dejó permite poco a poco ubicar y documentar una cantidad importante de objetos olvidados, que con frecuencia forman parte de colecciones públicas, tanto en museos europeos como mexicanos o estadounidenses. El presente artículo pretende dar una muestra de las aportaciones de este manuscrito todavía inédito.

Palabras clave Fuzier; manuscrito; arqueología; museos; Intervención francesa.

Abstract During the French Intervention in Mexico in 1862-1867, doctor Fuzier, then responsible of the French military hospital at Veracruz, engaged his spare time excavating and drawing an important corpus of archaeological objects, from well known major pieces, such as the Olmec colossal head from Tres Zapotes to minor figurines and even bones and skulls. The manuscript he left us allows slowly locating and documenting an important corpus of forgotten objects that frequently are part of public collections, in European, American and Mexican museums. The present paper aims to present a significant sample of what this still unpublished manuscript can provide.

Keywords Fuzier; manuscript; archaeology; museums; French Intervention. 
DOI: https://doi.org/10.22201/iie.18703062e.2020.116.2717

\author{
ROSARIO ACOSTA NIEVA \\ ERIC TALADOIRE
}

\title{
Jean-Baptiste Fuzier: del vómito negro al arte precolombino
}

ómo distraerse cuando se es un joven científico culto, aventurero y curioso, pero cuyas responsabilidades se limitan a remendar a uno que otro herido de guerra y a cuidar a los enfermos del vómito negro? Jean-Baptiste Fuzier llega a Veracruz en 1862 para reemplazar al doctor Lallemand, director del hospital militar francés destacado en el puerto de Veracruz, que había muerto del mismo mal en I862, casi al llegar a México. El Ministerio de Guerra francés envía entonces a este disciplinado militar de 38 años, que es inmediatamente nombrado director del hospital y ascendido tiempo después, en I864, al grado de médico principal de segunda clase. ${ }^{\mathrm{I}} \mathrm{Al}$ año de su llegada, Fuzier enferma también del vómito, pero sana después de una larga convalecencia.

Por ese tiempo, el mayor problema del puerto, más que los enfrentamientos con las tropas mexicanas, es el vómito negro, llamado también fiebre amarilla, una enfermedad viral transmitida por un mosco que con una sola picadura puede inocularla y cuyo padecimiento ataca el hígado y los riñones. El síntoma más impresionante es, precisamente, un vómito sangriento, del que tomó su nombre. Esta enfermedad hace terribles estragos en las tropas extranjeras, sobre todo al principio, cuando los organismos europeos no habían desarrollado todavía los anticuerpos de defensa necesarios para resistir a esta afección, propia de climas tropicales.

I. Anónimo, "Jean-Baptiste Fuzier”, Bulletin de la Médecine et de la Pharmacie Militaire, vol. 29, núm. 268 (París: abril de I880); Pierre Bonnette, La Légion Etrangère (I83I-I93I): ses prouesses, ses maladies, ses médecins (Tours: Imprimerie Tourangelle, 1935). 
Dado el aumento alarmante de enfermos y de muertos entre los recién llegados a Veracruz, se decidió que los siguientes barcos no anclaran en el puerto, sino que atracaran en la Isla de Sacrificios, situada a aproximadamente $3 \mathrm{~km}$ al este del puerto. Este sitio va a servir como "jardín de aclimatación”, llamado así en alusión al zoológico parisino de Vincennes que recibió el mismo nombre y era considerado como un pasaje obligado para que innumerables bestias exóticas, poco a poco y con muchos cuidados, se acostumbraran al clima del norte de Francia. Se trata entonces de un lugar de cuarentena que permite separar a los soldados sanos, que eran enviados al continente, de los enfermos, que recibían el tratamiento necesario hasta curarse o morir. Por ello, la isla va a servir también de cementerio. $\mathrm{Al}$ momento de cavar las fosas para inhumar a los soldados difuntos, se encontraban a menudo restos arqueológicos, pues el lugar era utilizado, en tiempos prehispánicos, como cementerio y los conquistadores espańoles supusieron que se trataba de restos de sacrificados. ${ }^{2}$

Con el tiempo y la experiencia adquirida en su tratamiento, el número de enfermos se redujo. El método de cura estaba suficientemente probado para que fuera eficaz. De la misma manera, las tropas, mejor preparadas y físicamente más resistentes, mueren menos y los sobrevivientes están inmunizados de por vida. Al mismo tiempo, los militares franceses traen soldados de África del Norte: entre ellos se encontraban unas tropas que venían de la región que hoy día ocupa Sudán. Aunque más resistentes que los europeos al clima tropical, los sudaneses también se vieron afectados por el vómito negro. Por la devoción en su cuidado, el doctor Fuzier recibe la decoración de la orden de Medjidié, fundada en $1852^{3}$ por el sultán turco Abdul Medjid para recompensar los servicios civiles y militares aportados al Imperio Otomano, del que Sudán formaba parte en ese entonces.

La región en general gozaba de una relativa calma, el número de enfrentamientos era bajo, aún si, de cuando en cuando, se producían guerrillas que causaban algunos heridos a los que, como director del hospital, Fuzier proporcionó ayuda médica. El joven galeno se encuentra entonces siguiendo una rutina cotidiana de cuidados médicos menores que distaba mucho de llenar sus aspiraciones de aventura. Es en esa época de calma que la pregunta ¿cómo distraerse? se presenta de manera apremiante.

2. Leonardo López Luján, "La Isla de Sacrificios y la arqueología en los albores del México independiente", Arqueología Mexicana, núm. I24 (noviembre de 2013): 80-87.

3. Se le concedió esta decoración de parte del gobierno egipcio. 
Su desarrollado sentido de la observación le había permitido percatarse, casi desde el principio, de las riquezas prehispánicas que contenía la región, por lo que decidió dedicar su tiempo libre a la composición de un repertorio de tales antigüedades. A pesar de ser arqueólogo amateur, ejercía un estricto control en cuanto a las piezas: sólo ilustraba aquellas que le parecían de interés suficiente, ya fuera por la rareza del material utilizado en su manufactura o por su valor estético o médico. Conforme a los escasos conocimientos de la época, Fuzier ilustra tanto piezas mayores como figurillas o malacates, con hincapié en los restos óseos y objetos de historia natural. Es necesario recordar también que no pertenece a ninguna corriente estética, sino que su afición se basa en su simple interés personal. En este sentido, sus dibujos no son representativos de ninguna concepción del arte prehispánico del siglo xIx. Su manuscrito constituye un documento de gran interés, ya que en él se encuentran desde objetos importantes y conocidos actualmente, hasta piezas de menor importancia artística, pero cuyo aporte para la mejor comprensión de la arqueología de la región puede revelarse útil e interesante. El objetivo de este artículo es, entonces, presentar de manera general dicho manuscrito y el contexto en el que fue concebido y elaborado.

\section{La Guerra de Intervención como contexto histórico}

España, Francia y Gran Bretaña decidieron mandar, el 7 de enero de I862, varios contingentes armados para apoderarse de Veracruz, el principal puerto mexicano, y obligar al gobierno a cumplir con deudas contraídas con dichas naciones o con simples ciudadanos extranjeros residentes en el territorio nacional. Ése fue el pretexto oficial de la Guerra de Intervención. España mandó casi 6,00o hombres, Inglaterra envió una flotilla con 700 infantes de marina a bordo, mientras que Francia aportó 3,000 soldados. Al enterarse Napoleón III del número importante de efectivos españoles, decidió aumentar la presencia francesa en México con 4,500 soldados más.

Pero si España y Gran Bretaña sólo buscaban recobrar el dinero de la deuda mexicana, Napoleón III tenía otros proyectos para ese país. ${ }^{4}$ La emperatriz

4. Jean Avenel, La Campagne du Mexique (1862-I867). La fin de l'hégémonie européenne en Amérique du Nord, Collection Campagnes et Stratégies. Edición Económica (París: Avenel, 1996); Alain Gouttman, La Guerre du Mexique, 1862-1867. Le mirage américain de Napoléon III. Pour l'Histoire (París: Perrin, 2008). 
Eugenia, mujer piadosa de origen español, y varios miembros del partido conservador mexicano, refugiados en Francia, lograron convencerlo de imponer en México un gobierno católico y favorable a las potencias europeas de la misma confesión. Puesto que la guerra de secesión mantenía ocupado al gobierno de los Estados Unidos, no pudieron oponerse a la llegada de las tropas europeas, ni arguyendo los principios de la doctrina Monroe que proclamaba desde 1823 que América era para los americanos.

Al percatarse de la maniobra imperialista, ingleses y españoles evitan toda implicación en la empresa y retiran sus tropas de México. El esquelético ejército francés marcha, entonces, rumbo a Puebla con 4,00o hombres, donde son vencidos por las tropas mexicanas el 5 de mayo de I862. Esta derrota no sólo hace evidente las dificultades que parecían ignorar, sino que inflige una seria humillación a la armada francesa, cuyo prestigio sin mancha había sido probado desde las batallas dirigidas por Napoleón I.

Con rapidez, para lavar la afrenta y levantar la moral de los hombres, se concibe otro proyecto. Primero, reforzando de manera significativa el ejército, los franceses logran apoderarse de Puebla y luego de la capital mexicana. Posteriormente, y bajo los auspicios del papa Pío IX, franceses y mexicanos en el exilio convencen a Maximiliano de Austria de aceptar la corona de emperador de México. Eso les permite obtener simultáneamente el apoyo militar de los belgas y de los austriacos, ya que Maximiliano está casado con Carlota, hija del rey de los belgas, y su hermano mayor es el emperador de Austria-Hungría, de modo que cada gobierno manda un regimiento.

Pero la victoria francesa resulta incompleta. Don Benito Juárez, presidente constitucional de México, y su gobierno legal lograron escapar y mantener vigente la existencia de un México republicano. Desde entonces, y por muchos años, la guerra continúa, fastidiosa y feroz. Las columnas francesas recorren toda la República, persiguiendo a Juárez y a sus partidarios. Se producen a veces batallas sangrientas y con mayor frecuencias escaramuzas, pero los franceses nunca logran capturar a Juárez, y su control del territorio es restringido y efímero. A lo largo de todo el territorio nacional se forman espontáneamente guerrillas autónomas que, aunque no reconocen la autoridad de Juárez, combaten a los franceses. Además, se reorganizan algunos antiguos oficiales republicanos cuyas tropas fueron desmanteladas después de la caída de la capital. A pesar de la sistemática y feroz represión, el país es incontrolable.

En I865, la victoria de los estados americanos del norte durante la guerra de secesión fragiliza la posición francesa en México. En efecto, el gobierno ame- 
ricano es favorable a Juárez quien recibe su ayuda: se alistan numerosos voluntarios norteamericanos en las filas del ejército juarista, se les facilita la compra de armas y se refuerza la presencia militar en la frontera con México, como clara advertencia al frágil imperio. Para empeorar la situación, Francia enfrenta un momento difícil, pues está amenazada por el poder creciente de Prusia. Los riesgos de una guerra próxima hacen necesario el regreso del ejército para proteger su propio territorio.

Poco a poco, y con pretextos falsos, Napoleón III retira sus tropas de México, dejando a Maximiliano aislado y a merced de los juaristas. Sólo le quedaban fieles unos cuantos voluntarios belgas, austriacos y franceses y las pocas tropas mexicanas conservadoras, con Mejía y Miramón al mando. Todos conocen el fin de la tragedia, en Querétaro: Maximiliano y sus generales son capturados y fusilados, en aplicación de las propias leyes imperiales. Don Benito Juárez regresa a México, retomando su lugar de presidente legítimo de la República mexicana.

El fracaso de la política imperial francesa, así como las consecuencias de la guerra para el pueblo mexicano, provocaron un resentimiento de corta duración entre ambos países que rompieron relaciones por algunos años. Los raros factores positivos de la Intervención son marginados y caen en el olvido los trabajos de los sabios franceses y mexicanos, miembros de las diversas comisiones científicas establecidas para llevar a cabo un estudio profundo de los aspectos geográficos, artísticos y culturales del país. ${ }^{5}$ Dichas investigaciones no interesan a los mexicanos, y en Francia la caída fulgurante del imperio acelera su extravío. Los principios difíciles de la tercera República francesa impiden el interés en las investigaciones y relatos de los antiguos partidarios de Napoleón III.

Cuando se reanudan las relaciones oficiales entre Francia y México, ya es demasiado tarde, y sólo algunos de los personajes que pelearon y trabajaron en México logran, como Charnay, ${ }^{6}$ continuar sus exploraciones. Todos los resultados recopilados por la gran mayoría de los investigadores de la Comi-

5. María Haydeé García Bravo y Eric Taladoire, "Más allá de los archivos de la Comisión Científica en México. Las aportaciones de las bibliotecas y de los museos", Arqueología Mexicana, núm. I38 (2016): 78-86.

6. Le Mexique 1858-1861. Souvenirs et impressions de voyage, comentado por Pascal Mongne (París: Ed. du Griot, 1987); Óscar Mauricio Medina Sánchez, "Désiré Charnay y la Commission Scientifique du Mexique. Una influencia francesa para la arqueología mexicana de la segunda mitad del siglo XIx", tesis para obtener el título de Licenciado en Arqueología (México: Escuela Nacional de Antropología e Historia, 2005). 
I36 ROSARIO ACOSTA NIEVA / ERIC TALAdoire

sión Científica francesa se traspapelan en los museos y los archivos donde, con un poco de suerte, se podrían todavía encontrar. Parte de los documentos de Fuzier han sido recientemente recuperados en el Museo del Servicio de Salud Militar del Val de Grâce. ${ }^{7}$

\section{Un esbozo biográfico}

Nacido en Grenoble en I824, Jean-Baptiste Fuzier empieza sus estudios en esta ciudad del este de Francia, antes de trasladarse a París para continuar su formación médica. A la edad de 22 años lo nombran cirujano (alumno) de $2^{a}$ división, en el Hospital Militar de Lille, y en agosto de 1852, con apenas 28 años, obtiene el grado de doctor en la Facultad de Medicina de la Universidad de París. ${ }^{8}$

A partir de ese momento se dedica por completo a su carrera de médico militar, pasando de un puesto a otro. Después de una breve estancia en Argelia, donde combate una epidemia de cólera, participa como médico mayor en las campañas de Italia, en I859. Casi de inmediato, se enrola como voluntario en la expedición a China, donde lo nombran jefe del Servicio de Salud. Toma parte en la batalla de Palikao, durante la cual es retratado por Beaucé, el pintor oficial del cuerpo expedicionario. Después del saqueo del palacio d'Yuen Min Yuen, unos soldados le regalan unas piezas de valor que prefiere cambiar por una escultura de Buda, por encontrarla más interesante desde un punto de vista antropológico. Al mismo tiempo, se apodera de dos piernas femeninas y procede a su estudio, pues quería entender las deformaciones de los pies. Este análisis constituye una de sus escasas publicaciones. ${ }^{9}$

Poco después de su regreso a Francia, en julio de 186I, se entera de la Guerra de Intervención, y de nuevo solicita su traslado a México para iniciar esta nueva aventura. Apenas desembarcado en Veracruz, enferma, pero logra recuperarse y, a los 38 años, toma posesión de su cargo como director del hospital, mismo que ejerció durante más de cinco años: desde mayo de I862 hasta noviembre de 1867 . Se dedica entonces a curar tanto a los soldados franceses enfermos o heridos, como a los voluntarios extranjeros e incluso a los habitan-

7. García Bravo y Taladoire, "Más allá de los archivos de la Comisión Científica en México", 78-86.

8. Véase n. I.

9. Jean-Baptiste Fuzier, De l'usage de la déformation des pieds chez les femmes chinoises (París: Victor Rozier, ed., 1862). 
tes de Veracruz. Su devoción como médico le valdrá varias medallas: además de la ya mencionada del Orden del Medjidié del Imperio Otomano, la de la Orden de Guadalupe, instaurada por Maximiliano en México, y la de la Legión de Honor en Francia. Al regresar a Francia, en I867, como médico principal de 2a clase, disfruta apenas de dos años de tranquilidad antes de regresar al combate en la guerra contra Prusia en 1870. Después de ser capturado por los alemanes durante la batalla de Metz, logra escaparse y continúa su carrera de médico militar en Burdeos. A partir de entonces, su vida aventurera se torna más tranquila, hasta su muerte en 1880 en París, con apenas 56 años.

Este rápido esbozo de una carrera activa nos permite tener una idea general de su personalidad. Es muy probable que fuera partidario del imperio. Su profundo sentido del deber, posiblemente resultado de su fe cristiana, quedó ampliamente demostrado en Veracruz donde destacó por su caridad, su falta de racismo y su afecto hacia los heridos y los enfermos. En el plan profesional, es obvio que se trata de un médico experimentado y dedicado, cuyo espíritu de aventura se manifiesta por su enrolamiento voluntario en dos expediciones a tierras lejanas de su Francia natal.

Esto lleva a examinar el otro lado de su personalidad, en el plano personal. Es probable que su formación médica desarrollara su curiosidad científica, su afición por los países exóticos (Argelia, China, México), y, quizá, su sensibilidad artística. Como lo hemos mencionado, aprovecha cada oportunidad para desarrollar investigaciones personales paralelas, como lo hizo en China, o para dedicarse a la pintura, como lo demuestra el documento que nos ocupa, sin ubicarse en una corriente artística precisa. En este sentido, vale la pena subrayar que, si su talento no permite incluirlo entre los artistas destacados del siglo XIX, su afición le proporciona un agudo sentido crítico y cierta prudencia con relación a las piezas posiblemente falsas que cruzaron su camino. Cuando tiene dudas sobre la autenticidad de una de ellas, lo menciona, y podemos comprobar que sólo dibujó aquellas que le parecían interesantes: como la amplia muestra de Melgar, ${ }^{10}$ de la cual sólo representó unas cuantas piezas. Su colección personal resulta modesta y no está constituida con relación al valor de los objetos, sino por su significación histórica o cultural.

La ambivalencia entre su rigor científico y su temperamento artístico es precisamente lo que da mayor interés a su manuscrito, en el que cada pieza

Io. Eric Taladoire y Jane MacLaren Walsh, “José María Melgar y Serrano ¿Viajero, coleccionista o saqueador?”, Arqueología Mexicana, núm. I29 (2014): 8I-85. 




I. Acuarela de una vasija maya de Campeche. Tomada de Fuzier, Mexique. Collection de dessins d'après nature, faits ou recueillis de I862 à 1867 , par le docteur Fuzier, médecin en chef à l'Ecole Polytechnique, ex Médecin en chef de l'hôpital militaire français de la Vera Cruz. I D'antiquités mexicaines trouvées dans la plupart dans l'Etat de Vera Cruz et d'après leur provenance. $2^{e}$ De crânes anciens déformés de types mexicains. Ms I8I, Musée du Quai Branly, fonds précieux, dibujos 4I5, $4 \mathrm{I} 6$. Musée du Quai Branly, París. Foto del autor.

está representada desde varios ángulos: de frente, de perfil y a veces en planta. Además, cada reproducción viene acompañada de comentarios sobre su procedencia, su aspecto y, cuando resulta factible, su contexto. Cabe mencionar que, a diferencia de los exploradores aventureros de principios del siglo XIX, como Waldeck, Fuzier busca la reproducción fiel y exacta de los detalles, aun si no tiene los conocimientos necesarios para interpretarlos. Lo atestiguan por ejemplo la calidad y la precisión de las acuarelas de una vasija maya de Campeche, con sus glifos (fig. I) o los detalles de las incrustaciones dentales de un cráneo de Campeche (fig. 2).

\section{El manuscrito}

El nombre oficial del manuscrito que nos ocupa es: "La colección de dibujos de objetos materiales, hechos o reunidos en México de I862 a I867 por el doctor Fuzier, médico jefe de la Escuela Politécnica, ex médico jefe del hospital militar francés de la Vera-Cruz". Cuenta con 63 folios que contienen un total de 55I dibujos y acuarelas, acompañados por diez páginas de comentarios y notas sobre cada una de las piezas ilustradas. Entre ellas se encuentran 2I fotos de tipo antropométrico y dibujos de fósiles. Por desgracia, el documen- 


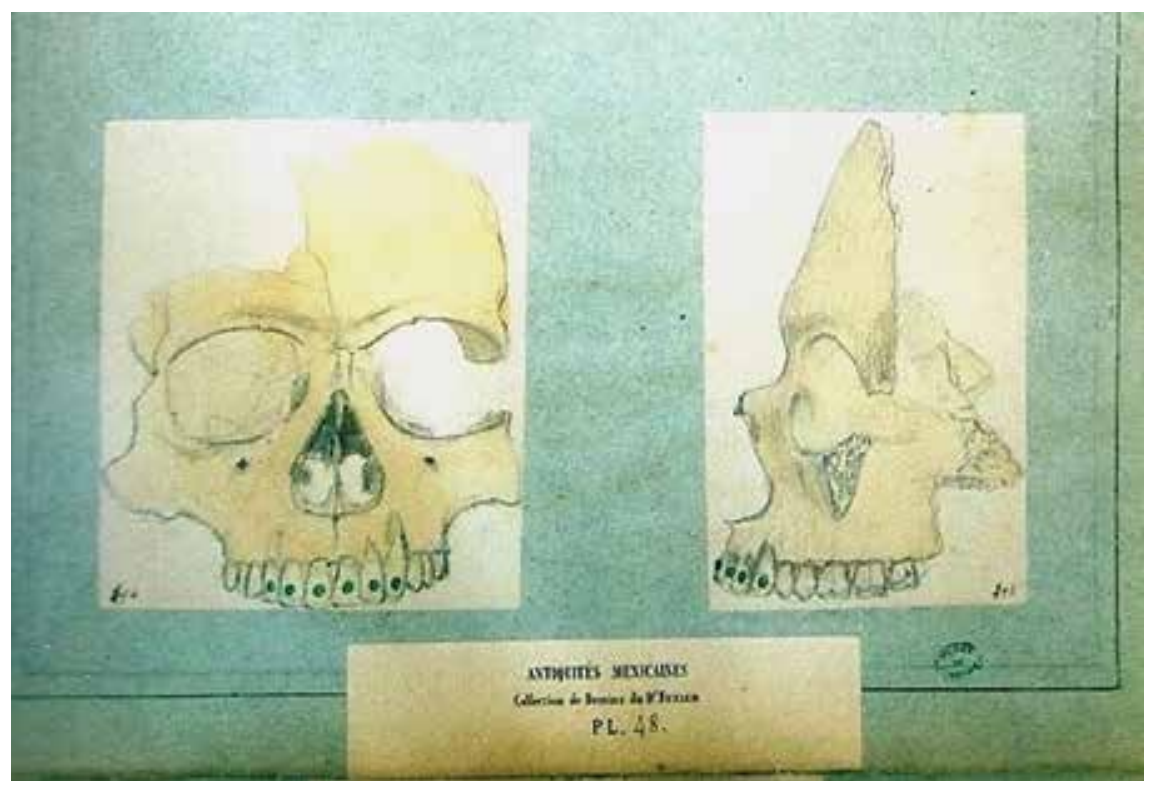

2. Dibujo con lápiz y colores de un cráneo encontrado en Campeche. Tomado de Fuzier, Méxique. Collection de dessins (vid. fig.I) fol. 46. Musée du Quai Branly, París. Foto del autor.

to, que pertenece en la actualidad a la biblioteca del Museo del Quai Branly, está incompleto, pues, hacia su parte final, faltan aproximadamente siete folios que se encuentran ahora en el Museo de Medicina Militar del Val de Grâce, dado el carácter de su contenido, con 26 ilustraciones referentes a las ciencias naturales y médicas. II

Un somero análisis del manuscrito hace evidente el gran cuidado con que Fuzier lo preparó. En efecto, cada dibujo a lápiz y cada acuarela fueron recortados y pegados en hojas de cartón gris que constituyen un soporte más resistente que el frágil papel utilizado en la época. La totalidad de las imágenes está numerada y remite a los comentarios que se encuentran en las hojas manuscritas. El mismo autor aporta correcciones, cuando constata inexactitudes en relación con la pieza original o cuando considera pertinente aumentar observaciones sobre el dibujo mismo.

II. García Bravo y Taladoire, "Más allá de los archivos de la Comisión Científica en México". 
Aunque se sabe que estuvo un tiempo en Tampico y en Campeche, considerando sus obligaciones profesionales, no es factible que tuviera la oportunidad de visitar otros lugares de México. Eso implica que gran parte de las piezas que él dibujó le fueron prestadas por amigos y conocidos que se habían enterado de su interés por el pasado prehispánico y de sus capacidades artísticas. En sus comentarios, nunca falta la información sobre las personas que le prestaron $\mathrm{u}$ obsequiaron los objetos. Entre los 2I nombres registrados, la mayoría se refiere a oficiales del ejército francés, tales como el capitán Lardy o varios colegas médicos. Pero llaman también la atención las referencias a coleccionistas conocidos, como Calpini, ${ }^{\text {I2 }}$ Gutiérrez y Victory y, principalmente, José María Melgar, el famoso descubridor de la cabeza olmeca de Tres Zapotes. Estos coleccionistas no dudaron en mostrarle sus propias adquisiciones, sabiendo que él trataba de constituir un repertorio y que no tenía interés en coleccionar las piezas por sí mismas. Éste es uno de los aspectos más importantes del manuscrito, ya que ilustra objetos a veces famosos, a veces desconocidos, proporcionando así una fuente inigualable de datos sobre piezas que, sin su registro, quedarían para siempre privadas de contexto.

Cabe aclarar que, a pesar de que el número total de dibujos es de 55I, la cantidad de piezas ilustradas es más reducida y corresponde a 378. Eso se justifica por el trabajo sistemático de Fuzier, quien en muchos casos proporciona vistas distintas de la misma pieza (figs. 3a y b). Por ejemplo, numerosas figurillas, como las del Occidente, se encuentran representadas de frente y de perfil para tener una mejor cobertura de los detalles que las caracterizan. En otras ocasiones, el autor ilustra piezas separadas e incluye un dibujo donde figuran los objetos en conjunto. Eso es especialmente válido para las 66 piezas que él mismo excavó en la Isla de Sacrificios.

En los folios, como en sus notas, Fuzier demuestra una lógica implacable y un certero carácter científico. Existen, sin embargo, algunas fallas en su metodología como la ausencia sistemática de escalas métricas y la falta de anotaciones dimensionales. Pero, básicamente, su trabajo presenta las piezas de manera ordenada, clasificadas según su procedencia. Los primeros folios incluyen las pocas figurillas del Occidente a las que tuvo acceso. En seguida, aparecen los objetos del centro de México, en seis folios. La parte más voluminosa del manuscrito está dedicada a 
a)

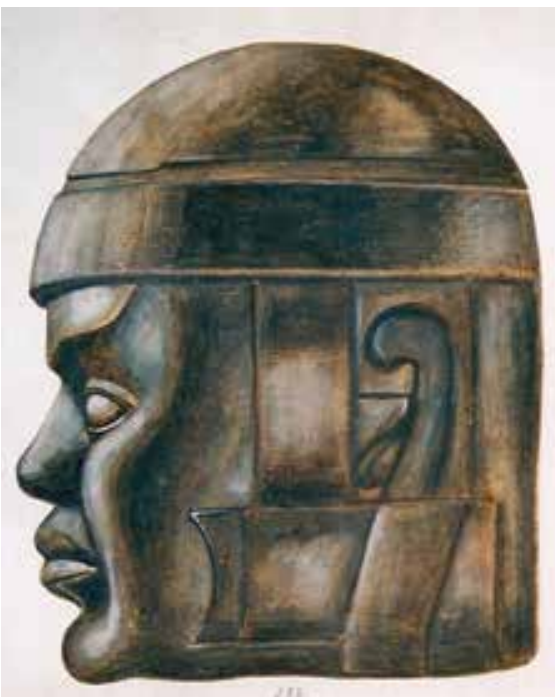

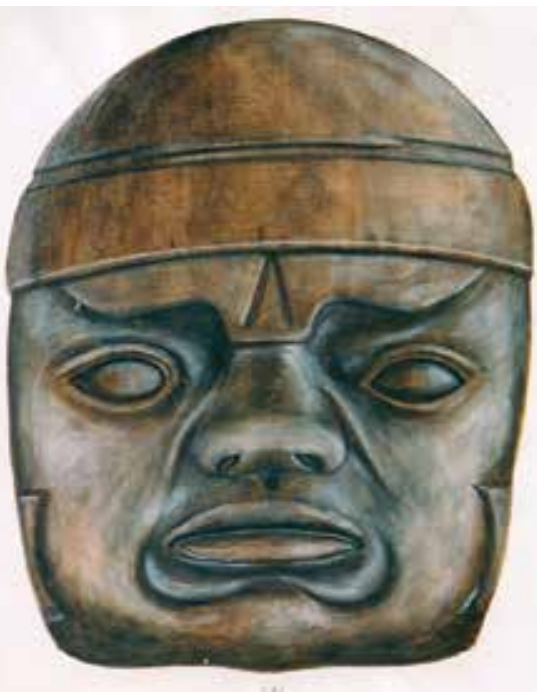

b)

3. Acuarelas de Fuzier de la réplica en madera de la cabeza de Tres Zapotes: a) vista lateral

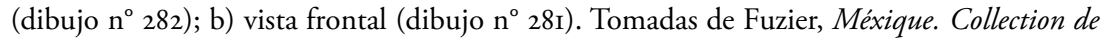
dessins (vid. fig. I). Musée du Quai Branly, París. Foto del autor.

las colecciones de la Huasteca ${ }^{\mathrm{I} 3}$ y de Veracruz, ${ }^{\mathrm{I} 4}$ lo que equivale a 32 folios. Los últimos 17 están dedicados a piezas procedentes de Oaxaca, Chiapas y Campeche. Resultaría imposible en un artículo abarcar toda la complejidad de la obra. Además, ya se publicaron en trabajos anteriores numerosas piezas que no necesitan repetirse aquí. ${ }^{15}$ Sólo se presentarán a continuación algunas piezas o aspectos representativos de la riqueza y de la diversidad del manuscrito.

13. Rosario Acosta Nieva y Eric Taladoire, "Datos inéditos sobre la arqueologa de la Huasteca: documentos antiguos, nuevas aportaciones", Arqueología Mexicana, núm. III (septiembre y octubre de 20II): 72-75.

I4. Annick Daneels y Eric Taladoire, "Fuzier: una contribución inédita a la arqueología de Veracruz", Arqueología Mexicana, núm. 98 (2009): 24-29.

I5. Taladoire y MacLaren Walsh, "José María Melgar y Serrano ¿Viajero, coleccionista o saqueador?”; Taladoire, "La colección poco conocida de arte prehispánico”; Acosta Nieva y Taladoire, "Datos inéditos"; Daneels y Taladoire, "Fuzier, una contribución”; Bernard y Taladoire, "Historia de dos piezas de estilo olmeca en Europa", Arqueología Mexicana, núm. I32 (2015): 74-75. 
DOI: https://doi.org/10.22201/iie.18703062e.2020.116.2717

I42

ROSARIO ACOSTA NIEVA / ERIC TALADOIRE

\section{La cabeza olmeca de Tres Zapotes y otras piezas de San Andrés Tuxtla}

Es bien conocido el descubrimiento del Monumento 'A' de Hueyapan, por José María Melgar y Serrano, en I862. Se trata, en efecto, de la primera cabeza olmeca de la que publicó varias notas (I869, I87I) ${ }^{16} \mathrm{Coe},{ }^{17}$ en I968, reproduce parte del artículo de Melgar, de donde se puede obtener la siguiente información: a una legua y media de una hacienda azucarera cuyo nombre se ignora, en las faldas occidentales de la sierra de San Martín, en un lugar llamado Hueyapan, en el cantón de Los Tuxtlas, se descubrió accidentalmente el monumento. El texto de Melgar viene acompańado de un grabado representando la cabeza vista de lado que, según Stirling, ${ }^{18}$ se hizo a partir de una reproducción en madera del original. ${ }^{19}$

El documento de Fuzier (fol. 28) proporciona dos dibujos suplementarios de la cabeza en madera: uno de frente y otro de perfil, registrados con los números 28I y 282 (figs. $3 \mathrm{a}$ y b). Aunque no disponemos de fechas para situar la cronología de los dos dibujos de Fuzier, éstos fueron, sin lugar a dudas, ejecutados entre I862 y I867, o sea varios años antes de la primera publicación de Melgar.

En cuanto a la procedencia del monumento, Fuzier aporta más precisiones:

Dibujo hecho a partir de una reproducción de madera de una enorme cabeza de 2 metros de diámetro, que se encuentra encima de una loma, cerca de Tlaliscoyan o cerca de Cosomoloapan. Cerca de Tlaliscoyan, en la hacienda Beauregard. El seńor Melgar, de Vera Cruz, que cree que esta cabeza representa a Moctezuma, la habría comprado. La reproducción en madera no sería exacta. ${ }^{20}$

I6. José María Melgar y Serrano, "Antigüedades mexicanas", en Sociedad Mexicana de Geografía y Estadística-Boletín, 2a época, núm. I (1969): 292-297.

17. Michael J. Coe, America's First Civilization (Nueva York: American Heritage Publishing, 1968).

I8. Matthew W. Stirling, Stone Monuments of Southern Mexico (Washington: Bureau of American Ethnology Bulletin, 1943), I38.

19. Taladoire y McLaren Walsh, "José María Melgar y Serrano ¿Viajero, coleccionista o saqueador?"

20. "Dessin fait d'après une reproduction en bois d'une énorme tête de $2 \mathrm{~m}$ de diamètre qui se trouve sur le sommet d'une petite montagne près de Tlaliscoyan, ou près de Cosomoloapan. Près Tlaliscoyan dans l'Hacienda Beauregard. Mr Melgar de Vera Cruz qui croit que cette tête représente celle del Montezuma l'aurait acheté. La reproduction en bois ne serait pas exacte", tomado del manuscrito de Fuzier. 
En apenas cuatro líneas queda confirmada la existencia de la reproducción de madera sobre la que se basan sus dibujos, ya que nunca vio él mismo el monumento. Precisa también la procedencia, asociándola al nombre de la hacienda. Los lugares Cosomoloapan, en realidad Cosamaloapan, y Tlaliscoyan corresponden a pueblos vecinos de la región. Por último, demuestra su sentido crítico, poniendo en duda la calidad del modelo de madera, y demuestra que, antes de presentar su hipótesis africana, Melgar había pensado en otras interpretaciones.

En su manuscrito, Fuzier incluye otras piezas compradas por Melgar. Lo más interesante es un grupo de objetos procedentes de la misma zona de Los Tuxtlas, porque pudieran resultar asociados a la cabeza. Entre ellos, destaca una curiosa vasija zoomorfa, con un ave dibujada en el borde, también de San Andrés Tuxtla. ${ }^{2 \mathrm{I}}$ Este recipiente trípode con paredes divergentes está adornado con grecas que, aunadas al color crema de la cerámica, hacen pensar en la posibilidad de una pieza olmeca. Fuzier precisa que, al interior de la vasija se encontraron unas vértebras fósiles (que ilustra) y restos de sulfuro de mercurio (cinabrio). Además, dibujó una figurilla antropomorfa en serpentina verde, cuyo aspecto evoca el estilo olmeca, y que también procedería de San Andrés Tuxtla. ${ }^{22}$ Ambas piezas se encuentran hoy día en colecciones públicas en Europa (respectivamente el Museum für Völkerkunde de Berlín, con el número Ca 7407, y El Palacio Madama en Torino, inv. top. 735).

\section{Las sepulturas de la Isla de Sacrificios}

La Isla de Sacrificios, situada a unos $3 \mathrm{~km}$ del puerto de Veracruz, es una de las ocho plataformas que emergen del sistema de arrecifes veracruzano. De apenas $340 \times 205 \mathrm{~m}$, alberga una gran diversidad de fauna y flora por lo que su interés ecológico es grande. Además, sabemos que desde tiempos prehispánicos ha sido probablemente un sitio funerario privilegiado; su estudio resulta entonces importante para la arqueología de la zona. Sin embargo, el hecho de haber servido como "jardín de aclimatación", durante la Guerra de Intervención, la expuso a numerosos saqueos intencionales o involuntarios. Es también

2I. Bernard y Taladoire, "Historia de dos piezas de estilo olmeca".

22. Bernard y Taladoire, "Historia de dos piezas de estilo olmeca"; Taladoire, "La colección poco conocida". 
probable que la isla fuera objeto de otros saqueos a lo largo de su historia, tal como lo sugiere la colección Cosmao-Dumanoir que se encuentra en el museo de Cannes. En 1841, el capitán Cosmao-Dumanoir aprovechó la breve estancia de su barco en Veracruz para recuperar objetos arqueológicos saqueados. El interés de la sección sobre la Isla de Sacrificios contenida en el manuscrito de Jean-Baptiste Fuzier reside en que rescata información de la época en que se produjeron los mayores disturbios en su registro arqueológico. Aunque se trate tan sólo de tres sepulturas, éstas representan un interés seguro para el estudio de las prácticas funerarias.

Las tres sepulturas excavadas por Fuzier están identificadas en su manuscrito con los números 3, 5 y 6 (tabla I). Por desgracia, no menciona el sector de la isla donde fueron encontradas, ni las condiciones del descubrimiento. Por otro lado, la ausencia de descripción precisa impide la obtención de los datos necesarios a la reconstitución exacta de su situación funeraria. Sin embargo, cada entierro se encuentra ilustrado por varios dibujos a lápiz que hacen hincapié en los cráneos. Dado que en los tres casos se trata de segmentos deformados intencionalmente, sería posible que el número de sepulturas excavadas fuera más importante, tal como lo sugiere la cantidad de objetos procedentes de la isla ilustrados en su documento, misma que se eleva a 66 piezas (anexo I). Es probable que sólo documentara los cráneos que presentaban deformación, debido al interés que esta práctica presenta para la medicina. Tal vez por esta razón no ilustra las sepulturas I, 2 y 4.

Al tomar en cuenta su limitado talento de dibujante, resulta sorprendente el cuidado y el detalle con que registró dichos cráneos. Es posible que, en este caso, el interés del médico prevaleciera sobre la expresión artística. Estas circunstancias nos permiten desarrollar un análisis más detallado de las tres diferentes deformaciones presentes.

\section{Sepultura 3}

Se trata de un solo individuo, al parecer adulto, en posición sedente con las piernas flexionadas. A pesar de contar con ocho ilustraciones, sólo dos de ellas están consagradas al entierro durante la excavación. En uno de los dos dibujos generales de la sepultura se aprecia una ofrenda colocada al costado izquierdo del cuerpo. Se trata, según el esbozo del autor, de una olla de tamaño considerable, pues el cuerpo de ésta parece ocupar un volumen similar al del cráneo (figs. 4a y b). 


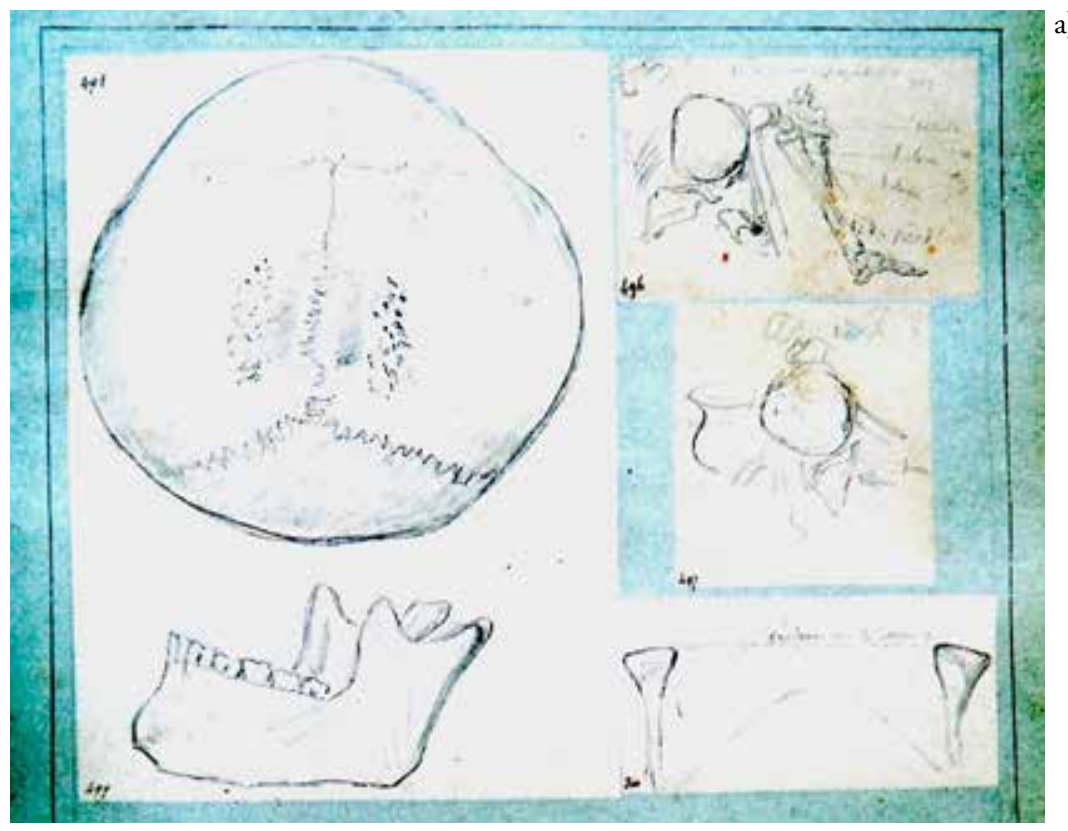

a)

4. La sepultura 3 de la Isla de Sacrificios: a) dibujos generales; b) diversas vistas del cráneo 3 de la Isla de Sacrificios por Fuzier. Dibujos a lápiz, tomados de Fuzier, Méxique.

Collection de dessins (vid. fig. I). Musée du Quai Branly, París. Foto del autor. 
I46 ROSARIO ACOSTA NIEVA / ERIC TALADOIRE

En el dibujo de perfil de la sepultura se aprecia el hecho de que el cráneo se desprendió de las vértebras cervicales y rodó hacia el tórax, siendo detenido por los fémures que se encontraban en posición vertical. Los pies tenían las plantas sobre el piso. Ambos dibujos están incompletos pues omiten precisar la posición de los miembros superiores y, al igual que el resto, carecen de escala. Es evidente que el autor estaba impresionado por la posición, sedente y flexionada, del cuerpo del difunto, y fue eso precisamente lo que trató de poner en evidencia, olvidando registrar otras características de la posición también importantes.

De las seis ilustraciones restantes, cuatro están consagradas al cráneo y dos a la mandíbula. Esta última se encuentra registrada en norma lateral izquierda y de dorso, en tanto que el cráneo fue dibujado en norma frontal, lateral derecha, dorsal y en planta. Esta detallada cobertura permite apreciar las características de la deformación que resulta muy curiosa, pues en norma frontal se aprecia un ensanchamiento de ambos parietales que debe dar como resultado una medida de diámetro transverso máximo, mucho mayor a la media normal. Se nota también una protuberancia evidente en la parte superior del frontal, a nivel del bregma, lo que aumenta su altura. En norma lateral, el aumento de la altura del frontal se confirma, en tanto que la curva frontal se encuentra aplanada. El occipital no parece afectado. En norma dorsal, de nuevo resalta el ensanchamiento de los parietales. El dibujo en norma vertical revela un desarrollo asimétrico de los parietales, siendo el derecho el más protuberante, lo que confirma una medida anormalmente grande del diámetro transverso máximo. Por el contrario, el diámetro antero-posterior máximo no parece anormal.

Con estos datos en mano, sería interesante tratar de deducir el tipo de aparato usado para producir tal deformación. Dado que los segmentos más afectados son el frontal y los parietales y que el primero presenta una curva anormal, resulta posible que el aparato deformatorio estuviera compuesto por una plaqueta colocada directamente sobre el frontal, entre la glabela y el bregma. Este aditamento pudo sujetarse por correas circundando el cráneo, pasando sobre las orejas, para amarrarlas al nivel de la nuca. Esto explicaría que el occipital no haya sido afectado y que los parietales aumentaran su volumen lateral. Aunque esta posibilidad no explica la protuberancia del sector bregmático del frontal, para la que evidentemente falta un elemento compresor, resulta la única viable a partir de la apreciación de los dibujos. Se podría, en efecto, deducir con mayor precisión el tipo de aparato a partir del estudio del cráneo, pues a partir del simple dibujo, no es posible apreciar los puntos y marcas menores de la compresión. 


\section{Sepultura 5}

Una vez más, de siete ilustraciones correspondientes a la sepultura 5, sólo una se relaciona con los restos óseos durante su excavación. Por desgracia es tan somera que resulta imposible determinar la posición exacta del difunto. Puesto que los miembros inferiores parecen flexionados y el cráneo se encuentra a menor profundidad que éstos, se podría sugerir que se trata de una inhumación primaria, de un solo individuo colocado en posición sedente. Sin embargo, las notas que acompañan el registro gráfico proporcionan información complementaria sobre las circunstancias del descubrimiento. Fuzier menciona que los restos fueron excavados a dos metros de profundidad y que no parecían estar contenidos en una fosa. ¿Como llegó hasta ahí? ¿Fue tanta su curiosidad que no reparó en la dificultad que implica remover dos metros de tierra con tal de descubrir un entierro? Quizás no. Lo que pudo haber pasado es que al excavar una fosa para unas víctimas del vómito negro, cuya profundidad, por razones de higiene, correspondería aproximadamente a dos metros, encontrara esta sepultura (fig. 5).

Sus notas mencionan también que tanto el cráneo como el resto de los huesos "fueron pasados por gelatina". Ante la ausencia de información adicional, sólo se puede sugerir que sumergir o barnizar los restos óseos con gelatina fue el método de consolidación usado, ya que menciona que el contacto con la tierra húmeda los había fragilizado.

De los seis dibujos restantes, dos corresponden a la mandíbula: uno en norma lateral derecha y el otro en norma dorsal. En ambos se nota la ausencia casi total de las piezas dentales, quedando in situ sólo dos incisivos derechos. Es evidente que no es posible determinar a partir del dibujo si esta pérdida es postmortem o ante-mortem. Si este último fuera el caso, se trataría de un individuo de edad avanzada.

El cráneo se encuentra ilustrado por tres dibujos en los que se aprecia la falta de la órbita y el maxilar izquierdo, al mismo tiempo que se nota la presencia de sólo dos dientes. Uno de los dibujos carece de orientación correcta, se trata de una visión fronto-vertical que pone en evidencia el desarrollo bilateral de los parietales, que forman dos lóbulos con una depresión a nivel de la sutura sagital. El diámetro transverso máximo que se aprecia en la imagen resulta entonces mayor que la media normal.

Otro dibujo presenta el cráneo en norma lateral derecha y pone en evidencia su pertenencia al tipo de deformación tabular oblicuo. En efecto, el frontal 


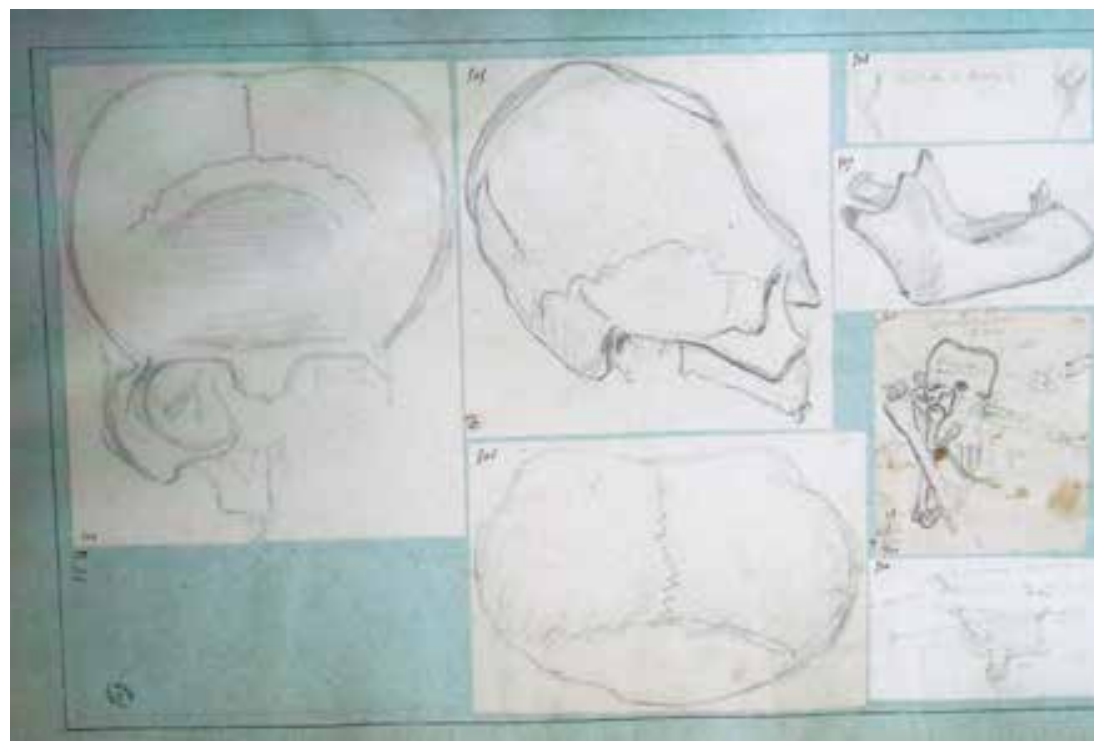

5. La sepultura 5 de la Isla de Sacrificios por Fuzier. Dibujos a lápiz, tomados de Fuzier, Méxique. Collection de dessins (vid. fig. I). Musée du Quai Branly, París. Foto del autor.

cuenta con una fuerte depresión de la curva, que provoca que los arcos superciliares sobresalgan de manera evidente, al igual que la parte superior de la sutura fronto-sagital. El occipital se encuentra también deformado, pues la presión ejercida sobre su escama produce una verticalización. El resultado de estas dos fuerzas encontradas, sobre el frontal y el occipital, produce un cráneo cuyo diámetro antero-posterior máximo es más reducido que el de un cráneo normal. Al mismo tiempo, como resultado de las presiones antes mencionadas, los parietales, además del desarrollo bilateral, presentan un desarrollo vertical importante. Esto da como resultado una altura basion-bregma mucho mayor que la normal. En esta misma ilustración aparece una protuberancia a nivel de la parte media de la sutura sagital, pero la imprecisión del dibujo no permite obtener mayores detalles.

La ilustración correspondiente a la norma vertical confirma lo arriba observado, es decir, un ensanchamiento lateral de los parietales, así como una fuerte compresión fronto-occipital, lo que da como resultado un cráneo con un diámetro transverso máximo mucho más desarrollado que el diámetro antero-posterior máximo. El séptimo dibujo resulta ilegible debido a su reducido tamaño, así como al trazo fino y la dureza del lápiz utilizado en su ejecución. 
6. Los cráneos de las sepulturas 3 y 5 de la Isla de Sacrificios dibujados por

Hamy, tomados de Ernest

Théodore Hamy; Mission

Scientifique au Mexique et dans l'Amerique Centrale, vid. n. 23, lám. X, figs. 7,8 .
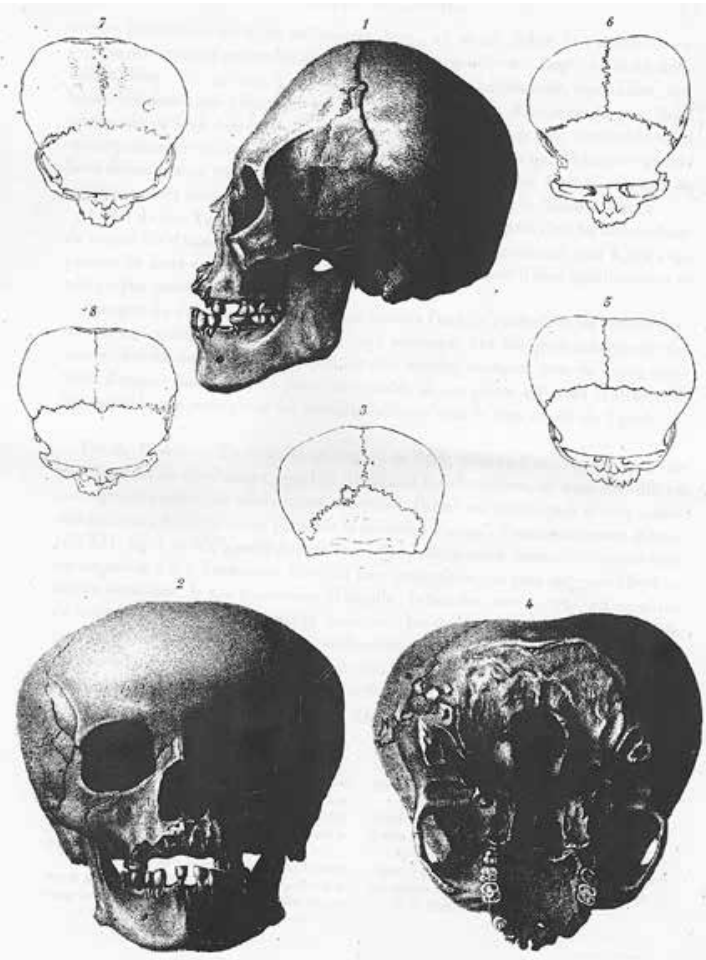

Este tipo de deformación implica un aparato deformatorio que ejerciera dos presiones localizadas en el frontal y el occipital. Bien que la del occipital pudiera corresponder a una plaqueta de madera, la del frontal debería ser diferente. En efecto, dada la fuerte depresión de la curva frontal, la presión en este sector no pudo haber sido ejercida por una plaqueta, lo que daría como resultado una forma recta, sino por un aparato convexo que produzca tal concavidad. La falta de una imagen correcta correspondiente a la norma frontal o dorsal imposibilita el análisis del tipo de correas utilizadas para sostener ambos planos de presión.

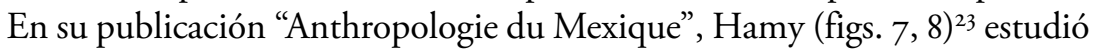
en exclusiva los cráneos de las sepulturas 3 y 5 que pudo manipular físicamen-

23. Ernest Théodore Hamy, Mission Scientifique au Mexique et dans l'Amérique Centrale, ouvrage publié par ordre du Ministre de l'Instruction Publique. Recherches zoologiques publiées sous la direction de M. H. Milne Edwards, membre de l'Institut. Première partie. Anthropologie du Mexique (París: Imprimerie Nationale, I89I). 
te (fig. 6). Los cráneos excavados durante la intervención se encuentran en la actualidad en las colecciones del Museo del Hombre en París, incluyendo los publicados por Hamy. ${ }^{24}$ Sus descripciones confirman nuestras observaciones sobre dibujo, apoyadas, además, por las cifras de las mediciones que efectuó sobre estas dos piezas.

\section{Sepultura 6}

Esta sepultura está ilustrada por apenas cuatro imágenes, una sola de las cuales corresponde a la posición del individuo. Se trata de un dibujo diminuto e incompleto que sólo deja entrever un cráneo en medio de unos huesos largos colocados de manera vertical y una vasija al costado derecho del mismo. A partir de tan escasa información, se podría deducir que el cuerpo se encontraba en posición sedente y probablemente flexionada, dada la posición de los huesos largos. Ninguna nota acompaña esta ilustración (fig. 7).

En cambio, el cráneo deformado se encuentra dibujado en norma frontal, lateral derecha y vertical. La falta de dibujo de la mandíbula podría ser el resultado de su ausencia física o de un olvido del autor. En norma frontal se hace evidente que el cráneo 6 presenta un desarrollo bilateral de los parietales, mismo que se encuentra confirmado por el dibujo en norma vertical. Esto da como resultado, al igual que para los cráneos 3 y 5 , un diámetro transverso máximo anormalmente amplio.

El análisis de la ilustración en norma lateral derecha revela una presión fronto-occipital que clasifica su deformación como tabular oblicua. Pero a diferencia del cráneo 5 que presenta una altura importante de la bóveda craneana, para el cráneo 6 esta altura es mucho menor, debido a que el plano de compresión del occipital se encuentra probablemente entre el opistocráneo y el opistion. Este plano de compresión pudo corresponder a un aparato recto, colocado de manera tangencial a la curva occipital inferior. El mismo tipo de aparato pudo utilizarse en el frontal, donde se aprecia un aplanamiento a nivel de la curva que comenzaría desde la glabela sin tocar la sección bregmática que, como consecuencia de la presión de la curva, se convierte en el punto más alto del crá-

24. María Haydeé García Bravo, "Colecciones antropológicas decimonónicas. La puesta en escena de la racialidad”, en Elke Köppen y Norma Blázquez Graf, coords., Memorias de las Jornadas Anuales de Investigación 2014 (México: Universidad Nacional Autónoma de MéxicoCentro de Investigaciones Interdisciplinarias en Ciencias y Humanidades, 2015), 85-103. 
7. Diversas vistas del cráneo 6 de la Isla de Sacrificios por Fuzier. Dibujos a lápiz, tomados de Fuzier, Méxique. Collection de dessins (vid. fig. I). Musée du Quai Branly, París. Foto del autor.

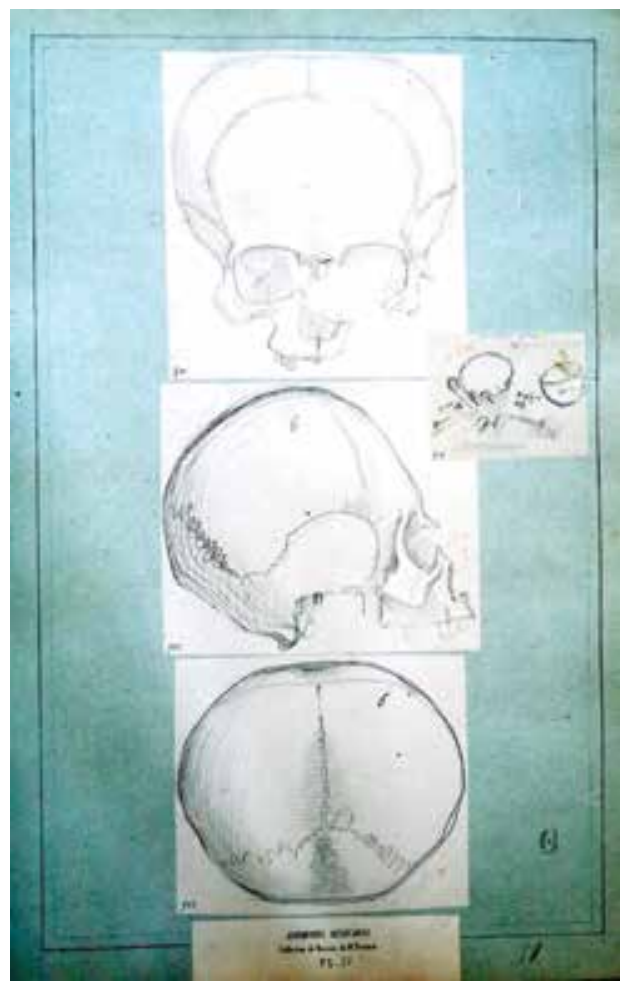

neo. Podría haberse tratado de una plaqueta colocada en forma directa sobre las cejas, abarcando los dos primeros tercios del frontal.

\begin{tabular}{cccccc}
\hline Núm. & Folio & Dibujo & NMI & Posición & Ofrendas \\
\hline 3 & 48,49 & $496,497,498,499,500,501,502,503$ & I & Sedente & I \\
5 & 50 & $504,505,506,507,508,509,510$ & I & Sedente $¿ ?$ & Ninguna ¿? \\
6 & $5 \mathrm{I}$ & $5 \mathrm{II}, 5 \mathrm{I} 2,5 \mathrm{I} 3,5 \mathrm{I} 4$ & I & Sedente $¿ ?$ & I \\
\hline
\end{tabular}

Tabla I. Los entierros de Isla de Sacrificios, dibujos y ofrendas asociadas.

Una vez más en los dibujos se nota la ausencia de numerosas piezas dentales. De hecho, sólo parecen estar presentes un incisivo lateral derecho, un canino y un molar del mismo lado, aunque en otra de las ilustraciones aparecen dos molares. Ante la falta de notas escritas, no se puede saber si su pérdida 
fue ante o postmortem, por lo que carecemos de indicios en cuanto a su edad al momento de la muerte.

La descripción detallada de las deformaciones craneanas presentes constituye un aporte significativo al conocimiento de esta práctica osteo-cultural en la región. Es de mencionar que, considerando la importancia del sitio en el contexto prehispánico, las publicaciones que le conciernen son escasas. Entre ellas, sólo podemos mencionar una nota de Batres, ${ }^{25}$ dos artículos de Du Solier y un estudio más amplio de Medellín Zenil, lo que no refleja cabalmente su importancia arqueológica como cementerio prehispánico.

\section{El cráneo de cuarzo de la colección Calpini}

Entre las piezas más problemáticas del manuscrito figura un pequeño cráneo de cuarzo (fol. 5, dib. 43). Según Fuzier, este objeto pertenecía a Zaverio Calpini, un coleccionista quien lo recolectó o lo compró en el centro de México ${ }^{26}$ y que dio partes de sus piezas al Museo Civico de Torino (Palazzo Madama). El cráneo forma parte actualmente de las colecciones del Palazzo Madama, con el número top. 73I. El mismo folio incluye otras ir piezas de la colección Calpini (cuadro 2). ${ }^{27}$ En sus comentarios, Fuzier precisa: "cráneo en cuarzo ahumado, con un agujero para colgar" ${ }^{28} \mathrm{El}$ dibujo representa un pequeño cráneo de cuarzo con una depresión en su parte superior.

\begin{tabular}{lll}
\hline \multicolumn{1}{c}{ Fuzier } & \multicolumn{1}{c}{ Descripción somera } & Torino \\
\hline Fol. 5, dib. 4I & Máscara en serpentina muy pulida & Top. 736 \\
Fol. 5 , dib. 42 & Cabeza de halcón en piedra café & Top. 540 \\
Fol. 5 , dib. 43 & Cráneo humano en cristal de roca & Top. $73 \mathrm{I}$
\end{tabular}

25. Leopoldo Batres y Zelia Nuttall de Pinard, La Isla de Sacrificios (México: Tipografía Económica, I9Io); Wilfrido Du Solier, "Isla de Sacrificios (entierros"), Revista de Educación (1938); A Reconnaissance on Isla de Sacrificios. Veracruz, México, Notes on Middle American Archaeology and Ethnology I-I4 (Washington: Carnegie Institution of Washington, 1943): 63-80; Alfonso Medellín Zenil, Exploraciones en la Isla de Sacrificios (Jalapa, Veracruz: Gobierno del Estado de Veracruz: 1955).

26. Taladoire, "La colección poco conocida de arte prehispánico".

27. Bernard y Taladoire, "Historia de dos piezas".

28. Tête de mort en cristal de roche fumé, transpercée pour la suspendre, Dibujo número 43, fol. 5. Calpini, México. 
DOI: https://doi.org/10.22201/iie.18703062e.2020.116.2717

JEAN-BAPTISTE FUZIER

\begin{tabular}{lll}
\hline \multicolumn{1}{c}{ Fuzier } & \multicolumn{1}{c}{ Descripción somera } & Torino \\
\hline Fol. 5, dib. 44 & Cúpula en obsidiana muy pulida & Top. 1245 \\
Fol. 5, dib. 45 & Placa circular en turquesa & \\
Fol. 5, dib. 46 & Tubo de jadeíta & Top. 497 \\
Fol. 5, dib. 47 & Tentetl en obsidiana & \\
Fol. 5, dib. 48 & Tentetl en obsidiana & Top. 490 ? \\
Fol. 5, dib. 49 & Tubo en obsidiana & Top. 497 \\
Fol. 5, dib. 50 & Pieza central de collar en serpentina verde & Top. 503 \\
Fol. 5, dib. 5I & Pieza central de collar en serpentina verde & Top. 498 \\
Fol. 5, dib. 5I bis & Figurilla de jade verde & Top. 735 \\
Fol. 40, dib. 394 & Placa de jade verde pulida, maya & Top. 728 \\
\hline
\end{tabular}

Tabla 2. Las piezas de la colección Calpini dibujadas por Fuzier y actualmente en el Palazzo Madama de Torino.

Desde mediados del siglo pasado, el tema de los cráneos de cristal ha provocado una amplia controversia entre científicos y partidarios del movimiento new age, de la que los trabajos de Jane Walsh ${ }^{29}$ presentan una reseńa completa. Todo empieza en 1943, cuando Mitchell-Hedges menciona que su hija descubrió un cráneo en cristal de roca en Lubaantun en 1924. Según los miembros de este movimiento esotérico, existen $\mathrm{I} 3$ cráneos, que poseen poderes paranormales. A pesar de que el investigador Joe Nickell comprobó que Mitchell-Hedges obtuvo el cráneo en una venta en Sotheby en 1943 por el precio de 400 libras esterlinas, muchos adeptos siguen convencidos de su autenticidad.

En 1966, estudios científicos controlados por el Museo Británico comprobaron que muchos de estos cráneos presentan marcas de pulidoras modernas, inventadas a finales del siglo xIx. Estudios complementarios de la Smithsonian Institution $^{30}$ lograron establecer que varios de ellos pertenecieron al anticuario francés Eugène Boban, quien los obtuvo en Alemania, donde fueron fabricados entre I867 y i897. Boban trató de vender a la Smithsonian uno de ellos, de

29. Jane MacLaren Walsh, "Crystal Skulls and Other Problems: Or, 'Don't Look it in the Eye”, en Amy Henderson y Adrienne L. Kaeppler, eds., Exhibiting Dilemmas: Issues of Representation at the Smithsonian (Washington/Londres: Smithsonian Institution Press, 1997), II6-I39; Jane MacLaren Walsh y Brett Toping, The Man Who Invented Aztec Crystal Skulls. The Adventures of Eugène Boban (Nueva York/Oxford: Berghahn, 2019).

30. MacLaren Walsh, "Crystall Skulls and Other Problems". 
tamaño más importante y sin ninguna cavidad superior, afirmando con falsedad que la pieza pertenecía a la antigua colección Fuzier. ${ }^{3 \mathrm{I}}$

Resulta entonces muy probable que Boban, enterado de la presencia de un cráneo entre los dibujos de Fuzier, se implicara en el proceso de falsificación y aprovechara el nombre ilustre del doctor para conferir cierta "autenticidad" a la pieza que intentó vender a la Smithsonian. En todo caso, no cabe duda que el cráneo del catálogo de Fuzier no corresponde a ninguna de las falsificaciones posteriores, pues ya existía antes de 1867 en la colección Calpini. Sin embargo, Jane Walsh ${ }^{32}$ señala que se registraron varios ejemplos de tales cráneos anteriores a la intervención de Boban, que serían también falsificaciones. ¿El cráneo ilustrado por Fuzier sería también el producto de una falsificación?

\section{Una figurilla de Jaina}

Las figurillas de Jaina y de la costa de Campeche rara vez ilustran elementos arquitectónicos. Los únicos ejemplares que se han podido encontrar hasta la fecha son algunas piezas ilustradas por Corson, ${ }^{33}$ que representan personajes sentados en especies de tronos. Además, una pieza del Museo Nacional de Antropología ${ }^{34}$ nos muestra a un individuo ricamente ataviado, sentado en un sillón muy elaborado y acompańado de dos enanos localizados a cada lado de la base (fig. 8a).

Llama entonces la atención la figurilla dibujada por Fuzier (fig. I2a) correspondiente al número 484 (fol. 46). Según sus notas, procede de la costa de Campeche y forma parte de un lote de objetos que incluye varios recipientes, otras figurillas y hasta un cráneo (fol. 48), que atestigua del origen funerario de ciertas piezas (fig. 2). No tenemos el nombre del donador, pero sabemos

3I. Pascal Riviale, "Eugène Boban, ou les aventures d'un antiquaire au pays des Américanistes", Journal de la Société des Américanistes, t. 87 (200I): 35I-362.

32. MacLaren Walsh, "Crystall Skulls and Other Problems".

33. Christopher Corson, Maya Anthropomorphic Figurines from Jaina Island, Campeche, t $\mathrm{I}$. (Ramona, Cal.: Ballena Press Studies in Mesoamerican Art, Archaeology and Ethnohistory, 1976).

34. Martha Foncerrada de Molina y Amalia Cardós de Méndez, Las figurillas de Jaina, Campeche, en el Museo Nacional de Antropología (México: Universidad Nacional Autónoma de México-Instituto de Investigaciones Antropológicas/Instituto Nacional de Antropología e Historia, I988), lám. 29. 
a)

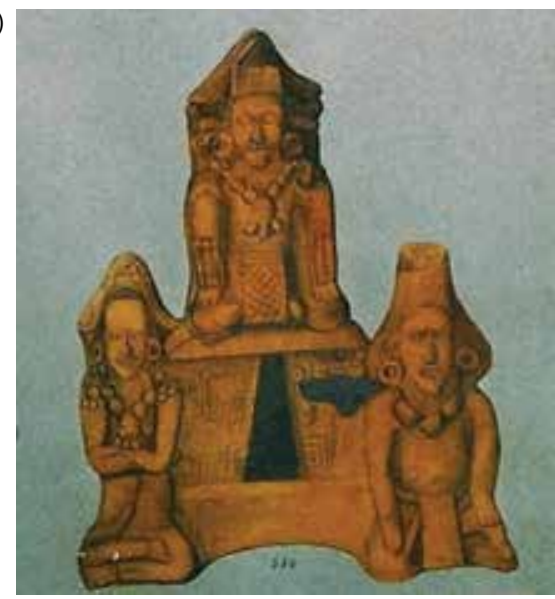

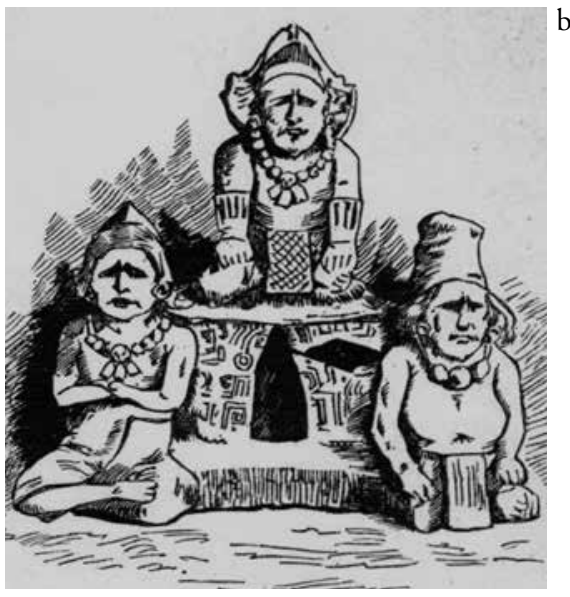

b)

8. a) Figurilla de Campeche, dibujo de Fuzier n ${ }^{\circ} 484$ (fol. 46, acuarela). b) Figurilla de Campeche de la colección Fuzier. Dibujos de Boban, The Boban Collection of Antiquities, Curios and Coins, also Books, Manuscripts and Printed. (Nueva York: George A. Leavitt \& co. New York. I886), núm. I7I.

que un tal Thuillier y el capitán Lardy proporcionaron a Fuzier varios objetos de Yucatán y de Campeche. Los comentarios del autor son los siguientes:

Muy extrańa pieza de cerámica fina, roja. Representa un héroe o un dios arrodillado. En su cabeza se ve la piel de un animal. Un collar. Una especie de escudo recubre su abdomen. Está dispuesto encima de una especie de trono, sostenido por dos cariátides arrodilladas. La de la derecha tiene también un penacho en forma de cabeza de animal. La pieza constituye un conjunto bien constituido, y presenta una composición que no he visto en ninguna otra pieza. Se trata tal vez de una trinidad divina, tal como existe en otras religiones. ${ }^{35}$

El dibujo de Fuzier permite una descripción un poco más detallada. Como él mismo lo menciona, la figurilla representa tres personajes, dos arrodillados

35. "Très remarquable pièce en terre cuite fine rouge. Représente un héros ou un dieu accroupi. Sur sa tête se voit la dépouille d'un animal. Collier. Une sorte d'écusson couvre l'abdomen; est placé sur une sorte de trône soutenu par deux sortes de cariatides accroupies. Celle de droite a aussi pour coiffure la tête dépouillée d'un animal. Le tout forme un ensemble bien groupé et qui respire un art de composition que je n'ai vu dans aucune autre pièce. Représente peut-être une trinité divine analogue à celles d'autres religions", en manuscrito de Fuzier. 


\section{I56 ROSARIO ACOSTA NIEVA / ERIC TALADOIRE}

y el tercero con las piernas cruzadas. El individuo central está dispuesto encima de un trono, o posiblemente de un templo, ya que la fachada presenta una bóveda característica de la arquitectura maya. Ambos lados de la fachada están decorados con círculos y grecas. Los dos personajes laterales llevan un maxtlatl, collares, orejeras y penachos, mientras que el central, barbudo, tiene un vestuario similar, pero más rico.

Hacia I89I, cuando Boban compró la colección de Fuzier a su heredera, ${ }^{36}$ esta figurilla formaba parte de la transacción. Él la menciona en su catálogo de I886, con el número I7I, y confirma que se trata de la misma pieza, al dar el nombre de Fuzier como propietario original. ${ }^{37}$ El dibujo que Boban dejó es de muy mala calidad (fig. I2b) y el texto que lo acompaña es una descripción errónea. Puesto que Boban la propuso a la Smithsonian sin que la ins-

36. Susana Guimaraes, Le Musée des antiquités américaines du Louvre (I850-1887). Une vision du collectionnisme américain au XIXe siècle, Mémoire de Maîtrise (París: Centre de Recherches en Archéologie Précolombienne. Université de Paris I, 1994); Riviale, "Eugène Boban, ou les aventures d'un antiquaire".

37. "Terracotta roja de tres dioses, formando una trinidad. Dos figuras sentadas, entre ellas las columnas de la puerta de un templo, cubiertas de jeroglíficos. Arriba de las columnas, parcialmente soportado por las dos figuras de abajo, está sentado Cuculcán, el dios principal. Sus manos están puestas sobre sus rodillas, su cara presenta una barba escasa, bien modelada, y tiene una expresión de fuerza y de tranquilidad. Su cabeza está cubierta por la de un venado, alrededor de su cuello está puesto un collar de perlas que se termina sobre su pecho con una cabeza humana o un cráneo. Un vestido con motivos entrecruzados cae entre sus piernas cruzadas. Aparte un maxtlatl sin motivos, la deidad masculina de la izquierda está desnuda, y sólo lleva un collar de tres cuentas. La deidad masculina de la izquierda está desnuda, y sólo lleva un collar de tres cuentas. La deidad de la derecha lleva una falda, su cuello está decorado con un collar similar al de la figura central. Reparado atrás, una columna fragmentada, por lo demás perfecta. I8 x I5. El Sr. Boban la considera en todos respectos una de las piezas más curiosa y valiosa de su colección. Era originalmente propiedad del Dr. Fuzier".

(I7I- Red terra-cotta of three gods, forming a trinity. Two figures, in seated postures, between them the pillars of a temple gate, covered with hieroglyphs. Above the pillars and partly supported by the two lower figures is seated Cuculcan, the principal god. His hands rest upon his knees, the face is slightly bearded, well modeled, and wears an expression of strength and repose; his head is covered with a deer's head, around his neck is fastened a collar of pearls terminating over his breast with a human head or skull; an apron of checkered pattern falls between his crossed legs. With the exception of a plain apron, the male deity at Cuculcan's left is naked, he wears necklace of three pearls; the goddess at his right wears a skirt, her neck is ornamented with necklace similar to the one worn by the central figure. Back mended, one column chipped, otherwise perfect. I $8 \times 15$. M. Boban considers this in every respect one of the most curious and valuable pieces of his collection; it was originally the property of Dr. Fuzier), en Boban. 
titución se mostrara interesada, esta figurilla estuvo probablemente presente en la subasta que Boban organizó en 1887. Se desconoce el paradero actual de esta pieza.

El aspecto particular de esta figurilla podría sugerir que se tratara de una falsificación, sobre todo considerando que otras piezas dudosas se encuentran entre los objetos de Campeche que Fuzier dibujó. Pero, tanto la presencia de fragmentos de cráneo que implica un contexto funerario bien documentado en Jaina, así como la existencia de la figurilla del Museo Nacional de Antropología, dejan abierta la hipótesis de que se trata de uno de los pocos ejemplares del arte de Jaina que representan elementos arquitectónicos.

\section{La placa de jadeita de la colección Calpini}

En el museo del Palazzo Madama, en Torino, figura una pequeña placa de jadeíta (fig. 9), posiblemente fragmentada, registrada en el catálogo con el número 2I (Inv. top. 728). Mide I0.5 $\times 15.5 \mathrm{~cm}$. Representa a un personaje sentado, mirando a su derecha, con un rico penacho de plumas y un collar.

Esta pieza, que procede también de la colección Calpini, aparece en los cuadernos de Fuzier con el número 394 del fol. 40 (fig. 9a). Fuzier comenta al respecto:

Muy bonita placa de jade verde pulido. Representa a un guerrero. El perfil del individuo se encuentra generalmente en Palenque y en Yucatán. La placa tiene un espesor promedio de I2 a I $5 \mathrm{~mm}$. Perforada transversalmente en su diámetro máximo de una canal estrecho, lo que debía permitir colgarla como adorno. Nos podemos preguntar cómo se ha podido perforar una piedra tan dura. El hierro y el acero eran desconocidos para los antiguos pueblos americanos. Pertenece al Seńor Calpini quien, durante una estancia en Veracruz, me la confió para dibujarla. ${ }^{8}$

38. "Très jolie plaque en jade vert très polie. Représente un guerrier. Le profil de la face est celui que l'on trouve généralement à Palenque et au Yucatan. La plaque a une épaisseur moyenne d'environ I2 à 15 millim. Est percée transversalement et dans son plus grand diamètre d'un canal étroit (diamètre d'une plume d'oie), ce qui permettrait sans doute de le suspendre au cou comme ornement. On se demande comment cette perforation a été obtenue, le fer et l'acier n'étant pas connu des anciens peuples de l'Amérique. Appartient à Mr. Calpini qui, de passage à Veracruz, me l'a confiée pour que je la dessine", en el manuscrito de Fuzier. 
DOI: https://doi.org/10.22201/iie.18703062e.2020.116.2717

I58 ROSARIO ACOSTA NIEVA / ERIC TALADOIRE

a)

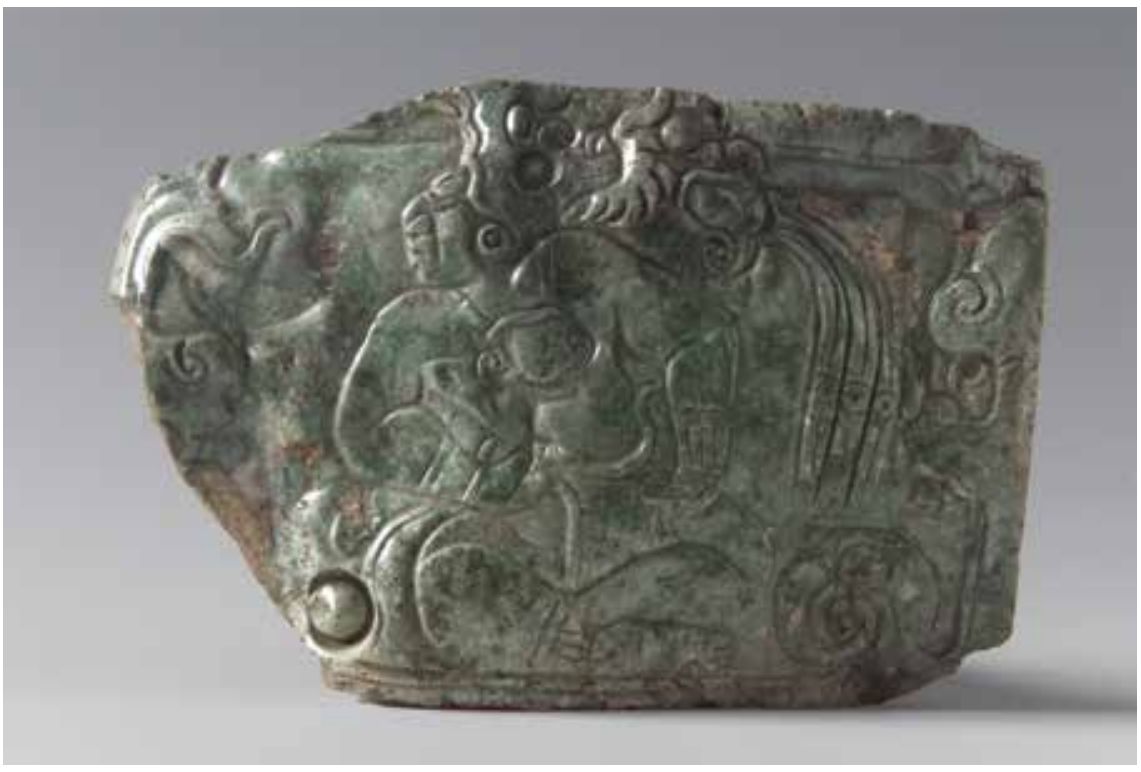

b)

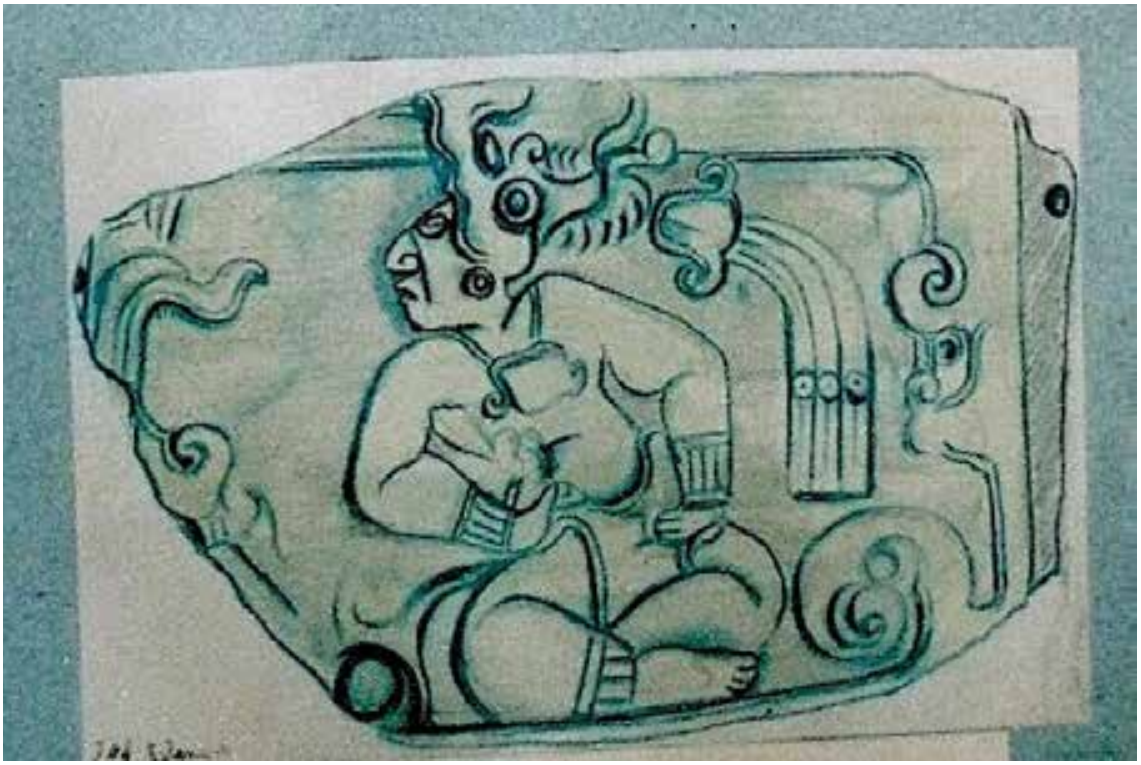

9. a) La placa de jadeita del Palazzo Madama, Torino (Top. 728). Cortesía del Palazzo Madama. b) La acuarela de Fuzier, Méxique. Collection de dessins (vid. fig. I), fol. 40, dib. 394. Musée du Quai Branly, París. Foto del autor. 
Si la perforación no se nota en la foto, Fuzier la ubicó de manera cuidadosa. Notamos de paso que la referencia a las representaciones humanas de Palenque implica que, además de dibujar, Fuzier tomaba el tiempo necesario para documentarse.

Sabemos que Calpini no viajó a la zona maya, por lo que podemos suponer que compró la placa en México. La referencia a Palenque como lugar de procedencia correspondería más bien a una aproximación, ya que este tipo de placa resulta más característica de la región de Nebaj, en Guatemala. ${ }^{39}$

\section{El devenir de las piezas}

Como se había mencionado con anterioridad, el trabajo de Fuzier no estaba alimentado por un afán de colección de piezas prehispánicas de valor monetario, sino por una curiosidad genuina por conocer la cultura antigua del lugar donde se encontraba por cuestiones de trabajo. Es por ello que sólo guardó para sí mismo un número relativamente reducido de objetos que no son ni los más bellos, ni los más prestigiosos. ${ }^{40}$ De hecho, como se puede constatar en sus donaciones al Museo del Hombre de París (ahora en el Museo del Quai Branly), su interés estaba sobre todo focalizado en piezas óseas, en particular en cráneos humanos, susceptibles de aportar un conocimiento técnico-médico, como en el caso de las deformaciones craneanas artificiales. El Museo del Hombre conserva 43 cráneos y fragmentos óseos entregados por Fuzier, entre ellos probablemente todos los que encontró en la Isla de Sacrificios. ${ }^{4 \mathrm{I}}$ Ya que su álbum incluye 2I dibujos de vestigios óseos, se puede considerar que se ha podido relocalizar la mayor parte de los restos humanos ilustrados.

Las piezas arqueológicas que pasaron por sus manos para ser registradas en dibujos o acuarelas fueron sistemáticamente restituidas a sus propietarios, varios de los cuales eran mexicanos, por lo que muchos objetos permanecieron quizás en su lugar de origen. Como ejemplo de lo anterior están las piezas del Museo Nacional de Antropología, ${ }^{42}$ del Museo de la Cultura Huasteca Ciudad Made-

39. Adrian Digby, Maya jades, revised edition (Londres: Trustees of the British Museum, 1972).

40. Comunicación personal con Marie-France Fauvet, 2009.

4I. García Bravo y Taladoire, "Más allá de los archivos de la Comisión Científica en México".

42. Du Solier, "Descripción de los diferentes tipos de cabecitas de barro cocido encontradas por la expedición científica mexicana”, informe inédito (México: Instituto Nacional de Antropología e Historia, s. f.). 
ro ${ }^{43}$ y de la Municipalidad de San Andrés Tuxtla en Veracruz. Fuzier conservó en particular los restos óseos, unas figurillas y algunos recipientes de sus excavaciones en la Isla de Sacrificios, en El Tejar y probablemente en Campeche. ${ }^{44}$ La mayor parte de su colección fue objeto de donaciones al Museo del Louvre (que se rehusó a aceptarlas), al Museo Broca, al Museo Antropológico del Jardín des Plantes o al Museo del Servicio de Salud Militar del Val de Grâce. ${ }^{45}$

Por otro lado, algunas piezas se trasladaron a Europa por las personas que las pillaron o recolectaron, y cierto número de ellas se encuentra hoy día en colecciones públicas de museos como el Museo de los Jacobinos de Auch, en el suroeste de Francia, ${ }^{46}$ o el Palazzo Madama de Torino (la colección Calpini, tablas 2 y 3 ).

\begin{tabular}{|c|c|c|c|}
\hline Lugar & Donador & Tipo de pieza & Cantidad \\
\hline Museo del quai Branly & J-B. Fuzier & $\begin{array}{l}4 \text { fragmentos de hueso } \\
\text { I pendiente de cerámica } \\
\text { I sello de cerámica } \\
6 \text { cuchillos de obsidiana } \\
6 \text { fragmentos de cuchillo }\end{array}$ & I8 objetos \\
\hline Museo del quai Branly & No identificado & $\begin{array}{l}\text { I fragmento de yugo } \\
\text { I recipiente zoomorfo, polícromo } \\
\text { (Huasteca } n^{\circ} 71.1893 .4 . I \text { ) } \\
\text { I cuenco (Isla de Sacrificios) } \\
\text { I cuenco polícromo (Campeche) } \\
\text { I estatua femenina (C-5274- } \\
32.680 .173 \text { ) } \\
4 \text { fragmentos de hueso }\end{array}$ & 9 objetos \\
\hline $\begin{array}{l}\text { Museo del Hombre, París } \\
\text { Departamento de Antropología }\end{array}$ & J-B. Fuzier & $\begin{array}{l}36 \text { cráneos humanos }+ \\
\text { fragmentos de } 2 \text { esqueletos }\end{array}$ & 43 objetos \\
\hline $\begin{array}{l}\text { Museo Nacional de } \\
\text { Antropología, México }\end{array}$ & No identificado & I3 cabecitas (Veracruz) & I3 objetos \\
\hline \multicolumn{4}{|c|}{$\begin{array}{l}\text { 43. Acosta Nieva y Taladoire, "Datos inéditos". } \\
\text { 44. Hamy, Mission Scientifique au Mexique. } \\
\text { 45. Claire Fredj, "François Jean-Baptiste Fuzier (I824-1880), un médecin-anthropologue à } \\
\text { Veracruz" (Ponencia presentada en el coloquio sobre la Intervención francesa en México, París, } \\
\text { noviembre de 2008). } \\
\text { 46. Pascal Mongne, Trésors Américains. Collections du Musée des Jacobins d'Auch (París: Editions } \\
\text { du Griot, I988). }\end{array}$} \\
\hline
\end{tabular}


DOI: https://doi.org/10.22201/iie.18703062e.2020.116.2717

JEAN-BAPTISTE FUZIER

\begin{tabular}{|c|c|c|c|}
\hline Lugar & Donador & Tipo de pieza & Cantidad \\
\hline $\begin{array}{l}\text { Museo de la cultura Huasteca } \\
\text { Ciudad Madero (Tamaulipas) }\end{array}$ & No identificado & Escultura antropomorfa & I objeto \\
\hline $\begin{array}{l}\text { Parque municipal de San } \\
\text { Andrés Tuxtla, Veracruz }\end{array}$ & No identificado & Cabeza olmeca de Tres Zapotes & I objeto \\
\hline $\begin{array}{l}\text { Smithsonian Institution of } \\
\text { Washington }\end{array}$ & Fuzier y Boban & $\begin{array}{l}7 \text { vasijas en cerámica } \\
\text { Una figurilla de El Tejar }\end{array}$ & 8 objetos \\
\hline $\begin{array}{l}\text { American Museum of Natural } \\
\text { History, Nueva York }\end{array}$ & ¿? & Estatua femenina & I objeto \\
\hline $\begin{array}{l}\text { Museo de los Jacobinos, Auch, } \\
\text { Francia }\end{array}$ & Fuzier & I incensario & I objeto \\
\hline $\begin{array}{l}\text { Museo de los Jacobinos, Auch, } \\
\text { Francia }\end{array}$ & Gutiérrez y Victory & Varias piezas & ¿? \\
\hline Museo Etnológico de Berlín & Bernardo Melgar & $\begin{array}{l}\text { Recipiente zoomorfo olmeca, } \\
\text { San Andrés Tuxtla }\end{array}$ & I objeto \\
\hline Palazzo Madama de Torino & Calpini & $\begin{array}{l}\text { Figurilla olmeca de piedra verde, } \\
\text { San Andrés Tuxtla (véase tabla 2) }\end{array}$ & II objetos $(+)$ \\
\hline $\begin{array}{l}\text { Museo Galletti di } \\
\text { Domodosolla }\end{array}$ & Calpini & Desconocido & ¿? \\
\hline $\begin{array}{l}\text { Museo de la Universidad de } \\
\text { Pennsylvania }\end{array}$ & Fuzier y Boban & $\begin{array}{l}\text { Fragmento de recipiente con una } \\
\text { representación humana }\end{array}$ & I objeto $(+)$ \\
\hline Total de piezas localizadas & & & $109+$ \\
\hline
\end{tabular}

Tabla 3. Lista de piezas arqueológicas ilustradas por Fuzier y localizadas en museos de México, Francia, Italia, Alemania y Estados Unidos, o sea un total de más de rog sobre las 378 representadas en el manuscrito.

Eugène Boban vendió a la Smithsonian Institution of Washington por lo menos siete piezas, incluyendo tres procedentes de las excavaciones de Fuzier en la Isla de Sacrificios. Según la información comunicada por Jane McLaren Walsh, ${ }^{47}$ se trata de las piezas siguientes (tabla 4 ).

47. Jane McLaren Walsh, comunicación personal, 2005. 
DOI: https://doi.org/10.22201/iie.18703062e.2020.116.2717

I62

ROSARIO ACOSTA NIEVA / ERIC TALADOIRE

\begin{tabular}{|c|c|c|c|}
\hline Pieza & Fuzier & Boban & Holmes \\
\hline $\begin{array}{l}\text { Olla con cuello decorado, } \\
\text { Isla de Sacrificios }\end{array}$ & $\begin{array}{l}\mathrm{n}^{\circ} 95,96,97,98 \\
\quad \text { folio } 14\end{array}$ & $\begin{array}{l}\mathrm{n}^{\circ} \mathrm{I} 32974, \text { coll. } \\
\text { Boban } \mathrm{n}^{\circ} \mathrm{I} 2\end{array}$ & $\begin{array}{c}\text { Record Unit 7084, } \\
\text { Box I }\end{array}$ \\
\hline $\begin{array}{l}\text { Vaso cilíndrico pintado, Isla } \\
\text { de Sacrificios }\end{array}$ & $\mathrm{n}^{\circ} \mathrm{IOI}$, folio $\mathrm{I} 5$ & & \\
\hline $\begin{array}{l}\text { Olla color café con motivos } \\
\text { pintados, Isla de Sacrificios }\end{array}$ & \multirow{2}{*}{\multicolumn{3}{|c|}{ I32969, coll. Boban n 30}} \\
\hline Tepalcate gris & & & \\
\hline $\begin{array}{l}\text { Recipiente cilíndrico gris, } \\
\text { Yucatán }\end{array}$ & $\mathrm{n}^{\circ} 445$, folio 43 & $\mathrm{n}^{\circ} \mathrm{I} 32967$ & \\
\hline Cuenco grisáceo, Yucatán & & $\begin{array}{c}\mathrm{n}^{\circ} \mathrm{I} 32966, \text { coll. Boban } \\
\mathrm{n}^{\circ} 182 \text { o I } 66 ?\end{array}$ & \\
\hline Figurilla, El Tejar & $\begin{array}{c}\text { Folio } 24 \text {, dib. } \\
233 \text { y } 234\end{array}$ & $\mathrm{n}^{\circ}$ Boban 255? & $\begin{array}{c}\text { Record Unit 7084, } \\
\text { Box I }\end{array}$ \\
\hline
\end{tabular}

Tabla 4. Lista de las piezas dibujadas por Fuzier, en la Smithsonian Institution of Washington.

El recipiente cilíndrico gris de Yucatán ( $\mathrm{n}^{\circ} 445$, fol. 43) posiblemente se ha quebrado después de que Fuzier lo dibujara (fig. Io). En los papeles de Holmes se nota la presencia de una figurilla, también dibujada por Fuzier, que proviene de sus excavaciones en El Tejar. No sabemos todavía si la compró la Smithsonian.

En la subasta consecutiva a la muerte de Fuzier, donde Boban adquirió la mayor parte de la colección, otros coleccionistas como el conde de Lestrange compraron algunas piezas que entraron así en los circuitos de las colecciones privadas y finalmente se ha perdido la pista de algunas de ellas.

Como se puede apreciar, el número de piezas identificadas y localizadas, aunque en aumento regular, es todavía limitado en comparación con el trabajo llevado a cabo por Fuzier. ¿Pero cuántos de los objetos registrados en su manuscrito se encuentran en bodegas de diferentes instituciones, tanto en el continente americano como en el europeo, sin que se tenga idea de su proveniencia, contexto o pertenencia cronológica? Según Jane McLaren Walsh, ${ }^{8}$ tres piezas de la colección Fuzier se encontrarían en el Museo de la Universidad de Pennsylvania. Por lo menos, la presencia de un fragmento de un recipiente con una

48. Jane McLaren Walsh, comunicación personal, 2005. 
Io. Recipiente cilíndrico gris, ahora en la Smithsonian Institution of Washington. Fuzier, Méxique. Collection de dessins (vid. fig. I), n 445, f. 43). Cortesía de Jane Walsh.

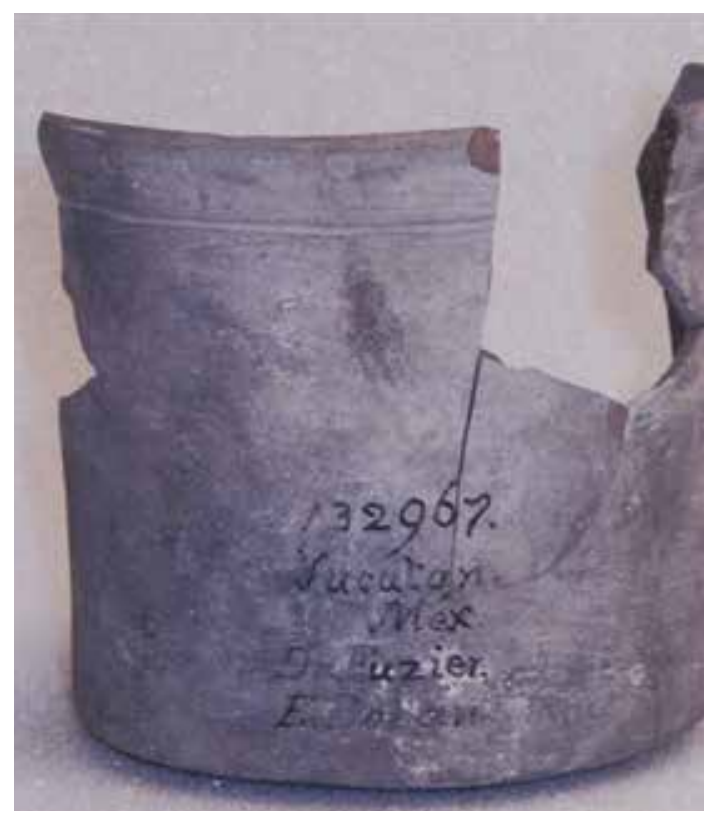

representación humana, procedente de Puebla (Fuzier, fol. 7, dib. 55), registrada con el $n^{\circ}$ L.82-28I, está confirmada. Otra pieza, una olla con una representación humana grotesca, entró a las colecciones del Royal Ontario Museum a principios del siglo pasado, con el número 21882. Hasta la fecha, no se ha podido localizar. Llama la atención el término grotesca, muy en conformidad con el interés personal del médico.

\section{El interés del manuscrito}

Aunque su fama de dibujante se había extendido de la región de Veracruz hasta otras partes de México, Fuzier está lejos de ser considerado un artista importante de su siglo. En efecto, algunos de sus bocetos presentan pequeñas imprecisiones, atribuibles al ojo europeo no familiarizado con la estética prehispánica, lo que modifica ligeramente la apariencia de algunas piezas. Tal sería el caso de las urnas zapotecas cuya iconografía compleja necesita una comprensión que sobrepasa los escasos conocimientos de Fuzier. Al contrario, cuando se trata de vasijas, de cráneos, logra dibujarlos sin dificultad. Sin embargo, su identificación 


\section{I64 ROSARIO ACOSTA NIEVA / ERIC TALADOIRE}

resulta posible para el especialista en el tema o la región que representa la imagen estudiada. Además, los objetos ilustrados están siempre acompañados por la información de su procedencia, aunque ésta sea a veces aproximada. Tal es el caso de las pocas piezas del Occidente, encontradas "entre Tepic y Guadalajara”, lo que implica una vasta área geográfica de investigación, pero que facilita, al menos, su ubicación regional. Como es evidente, no se puede culpar al autor de tales lagunas en el conocimiento, ya que tuvo siempre la conciencia científica necesaria para registrar la información proporcionada por los propietarios.

Aun tomando en cuenta los inconvenientes arriba mencionados, es innegable que la obra de Jean-Baptiste Fuzier suministra datos inestimables de los que, sin su intervención, no tendríamos noticia. Recordemos que aunque Melgar descubrió la cabeza monumental de Tres Zapotes, Fuzier fue el primero en dibujarla y documentarla. Además, durante sus excavaciones en la región de Veracruz descubrió iı6 piezas, procedentes de sitios entonces desconocidos y quizás parcialmente destruidos en el presente, como El Tejar. ${ }^{49}$

Sus exploraciones se llevaron a cabo con un rigor científico raro para su época: describe con detalle su metodología, ilustra correctamente el material y, con la sola excepción de la Isla de Sacrificios, localiza con precisión los pozos. En efecto, en sus trabajos de la Isla de Sacrificios, omitió cierta información relevante, pero obtuvo una colección consecuente por el volumen importante del material recuperado. Esto constituye una aportación valiosa, tanto para la arqueología, pues registró la posición de los cuerpos inhumados, como para la antropología física, ya que dibujó de manera detallada las diferentes modalidades de deformación craneana.

Se podrían citar otros ejemplos de los aportes de su manuscrito, pero resulta más conveniente abordar el tema general del valor histórico y arqueológico de los archivos del periodo de la intervención. Como se ha mencionado con anterioridad, el fracaso de la Guerra de Intervención provocó, por varios años, una ruptura en las relaciones entre Francia y México. Este lapso fue suficiente para ignorar muchos de los descubrimientos, tanto de los miembros mexicanos como de los franceses que colaboraron con la Comisión Científica francesa. Para citar sólo algunos ejemplos, son muy escasas, aún en México, las menciones al trabajo de Ramón Almaraz ${ }^{50}$ que excavó en Teotihuacan. Dicha

49. Daneels y Taladoire, "Fuzier: una contribución".

50. Ramón Almaraz, “Apuntes sobre las pirámides de San Juan Teotihuacán”, en Memorias y trabajos ejecutados por la Comisión Cientifica de Pachuca (México: Ministerio de Fomento, 1865), 349-358. 
exploración proporcionó el primer documento hecho por Méhédin de pintura mural conocido para el sitio. ${ }^{51}$ Los dibujos de Méhédin ${ }^{52}$ también han pasado inadvertidos por más de un siglo, a pesar de su alta calidad. Sólo en tiempo reciente se comprobó que, entre ellos, figuraban ilustraciones muy precisas de la pirámide de Xochicalco, ${ }^{53} \mathrm{o}$ un dibujo de un bajorrelieve de Toniná, el M.27. Las investigaciones recientes conducidas por Haydeé García Bravo comprobaron también que muchos de los objetos trasladados desde México, incluyendo piezas tan frágiles como huesos y cráneos, pueden recuperarse en las colecciones públicas, donde han sido almacenadas desde i867. ${ }^{54}$

El manuscrito de Fuzier forma parte de esas contribuciones olvidadas que merecen salir a la luz pública, para evaluar sus aportaciones y aprovechar los aspectos que podrían enriquecer nuestro conocimiento del pasado prehispánico mexicano. Sitios abandonados o destruidos, objetos extraviados o privados de contexto podrían recuperar su significado; arqueólogos, aventureros y exploradores ignorados vuelven a la actualidad para aumentar nuestros conocimientos. A pesar de algunas carencias, el manuscrito de Jean-Baptiste Fuzier constituye un valioso descubrimiento pues no se encuentran con frecuencia documentos tan detallados ni tan ricos en información de la que pueden obtener beneficios tanto la investigación arqueológica como los museos. Estos trabajos contribuyen a la ampliación del conocimiento del pasado prehispánico y del patrimonio nacional mexicano.

La solución ideal sería la publicación de los folios de Fuzier en su totalidad, a fin de proporcionar un utensilio de trabajo válido. Tal edición pondría a la disposición de los investigadores interesados la documentación necesaria para reubicar el contexto y la significación cultural de numerosos objetos arqueológicos mediante el uso prudente y crítico de los datos y de las imágenes. Además, los nombres de los coleccionistas registrados por Fuzier representan diferentes brechas de investigación que abren nuevas perspectivas

5I. Frédéric Gerber, Christian Nicaise y François Robichon, Un Aventurier du Second Empire. Léon Méhédin (I828-1905) (Rouen: Bibliothèque Municipale de Rouen, 1992); Eric Taladoire y Frédéric Gerber, "I865: Identification of 'Newly' Discovered Murals from Teotihuacan”, Mexicon XII, núm.I (I990): 6-9.

52. Gerber Nicaise y Robichon, Un Aventurier du Second Empire; Taladoire y Gerber, "I865: Identification of Newly Discovered Murals".

53. Leonardo López Luján, “The Aztecs' Search for the Past”, en Aztecs (Londres: The Royal Academy of Arts, 2002), 22-29.

54. García Bravo y Taladoire, "Más allá de los archivos de la Comisión Científica en México". 
I66 ROSARIO ACOSTA NIEVA / ERIC TALADOIRE

de entendimiento sobre la manera en que se formaron colecciones públicas y privadas. 55 Una publicación de este género nos beneficiaría a todos pues sería una aportación para los interesados en la recuperación del pasado prehispánico mexicano. \$

\section{Anexo I}

Registro de las piezas dibujadas por Fuzier procedentes de la Isla de Sacrificios

\begin{tabular}{|c|c|c|}
\hline Número del dibujo & Identificación de la pieza & Observaciones \\
\hline 85 & Fragmento de olla & \\
\hline 86 & Cuenco rojo con paredes evertidas & \\
\hline 87 & Cuenco con el borde externo inciso & Asociado con cráneo 6 ? \\
\hline 88 & Cuenco con el borde externo inciso & Asociado con cráneo 6 ? \\
\hline 89 & Cuenco de color gris, con asas. & Asociado con cráneo 6 ? \\
\hline 90 & Pequeńo plato de cerámica roja & \\
\hline 9I & Pequeño plato de cerámica roja & \\
\hline 92 & Pequeńo plato, pintado en su parte interna & \\
\hline 93 & Olla, con pintura externa & Smithsonian \\
\hline 94 & Cuenco trípode & \\
\hline $95,96,97,98$ & Pequeña olla con dibujos geométricos pintados & \\
\hline 98 bis & Fragmento de cerámica zoomorfa & \\
\hline 99, I00 & Cuenco trípode, con motivos pintados & \\
\hline IOI & Vaso pintado policromo & \\
\hline 102 & Florero rojo & \\
\hline IO3, $\mathrm{IO} 4$ & Recipiente zoomorfo (frente y perfil) & \\
\hline I05 & Pequeña olla con motivos en la pansa & \\
\hline Iosbis & Pequeńa olla con motivos en la pansa & \\
\hline I06, 107 & Vaso cilíndrico, grabado y pintado. & \\
\hline IO8 & Vaso cilíndrico, inciso en la orilla & \\
\hline 109 & Vaso zoomorfo (ave ?) & \\
\hline IIO, III & Cuenco policromo & \\
\hline II2 & Cuenco policromo & \\
\hline
\end{tabular}

55. Taladoire, "La colección poco conocida de arte prehispánico". 
DOI: https://doi.org/10.22201/iie.18703062e.2020.116.2717

JEAN-BAPTISTE FUZIER

\begin{tabular}{|c|c|c|}
\hline Número del dibujo & Identificación de la pieza & Observaciones \\
\hline II3 & Pequeña cuchara & \\
\hline II4 & Incensario trípode & \\
\hline IIS & Incensario antropomorfo & \\
\hline II6 & Otro fragmento del incensario anterior & \\
\hline II7 & Mango de incensario & \\
\hline II8, II9 & $\begin{array}{l}\text { Fragmento antropomorfo de incensario (frente } \\
\text { y perfil) }\end{array}$ & \\
\hline $\mathrm{I} 2 \mathrm{O}$ & Mango de incensario & \\
\hline I2I, I22 & Cabeza antropomorfa de piedra & \\
\hline $\mathrm{I} 23, \mathrm{I} 24$ & Malacate (frente y perfil) & \\
\hline $\mathrm{I} 25, \mathrm{I} 26$ & Malacate (frente y perfil) & \\
\hline $\mathrm{I} 27, \mathrm{I} 28$ & Malacate (frente y perfil) & \\
\hline $\mathrm{I} 29, \mathrm{I} 30$ & Malacate (frente y perfil) & \\
\hline I3I & Pequeño disco de cerámica con motivos & \\
\hline $\mathrm{I} 32, \mathrm{I} 33$ & Piedra roja, asociada con una sepultura & \\
\hline 134,135 & Cabeza de figurilla humana (frente y perfil) & \\
\hline I36, I37 & Cabeza de figurilla humana (frente y perfil) & \\
\hline $\mathrm{I} 38, \mathrm{I} 39, \mathrm{I} 40$ & Cabeza de figurilla humana (frente y perfil); motivo & \\
\hline I4I & Torso de figurilla & \\
\hline $\mathrm{I} 42, \mathrm{I} 43$ & Cabeza de figurilla humana (frente y perfil) & \\
\hline I44 & Cabeza de figurilla humana. & \\
\hline $\mathrm{I} 45, \mathrm{I} 46$ & Ídolo de cerámica & \\
\hline I47 & Estatua de piedra (I.40 m de altura) & Estaría en Veracruz \\
\hline I 48, I 49 & Figurilla silbato antropomorfa (frente y perfil) & \\
\hline I5O, I5I & Figurilla silbato zoomorfa (frente y perfil) & \\
\hline 152 & Figurilla silbato zoomorfa & \\
\hline I53, I54 & Figurilla silbato antropomorfa (frente y perfil) & \\
\hline 155,156 & Figurilla zoomorfa (mono ?) & \\
\hline 157,158 & Figurilla silbato antropomorfa (frente y perfil) & \\
\hline I59 & Figurilla zoomorfa (felino?) & \\
\hline I6o, I6I, I62, I63 & Cuatro fragmentos de mandíbula de animales. & Asociados a las sepulturas. \\
\hline I64 & Núcleo de obsidiana & Museo del Quai Branly? \\
\hline
\end{tabular}


DOI: https://doi.org/10.22201/iie.18703062e.2020.116.2717

I68

ROSARIO ACOSTA NIEVA / ERIC TALADOIRE

\begin{tabular}{cll}
\hline Número del dibujo & \multicolumn{1}{c}{ Identificación de la pieza } & \multicolumn{1}{c}{ Observaciones } \\
\hline I65 & Núcleo de obsidiana & Museo del Quai Branly? \\
I66 & Fragmento de hacha de pedernal & Museo del Quai Branly? \\
I67 & Punta de proyectil & Museo del Quai Branly? \\
I68 & Punta de proyectil (obsidiana) & Museo del Quai Branly? \\
I69 & Punta de proyectil (pedernal) & Museo del Quai Branly? \\
I70 & Punta de flecha de pedernal & Museo del Quai Branly? \\
I7I & Punta de proyectil (obsidiana) & Museo del Quai Branly? \\
I72, I73 & Puntas de proyectil (obsidiana) & Museo del Quai Branly? \\
\hline
\end{tabular}

Total: 66 piezas, 89 dibujos (varias piezas están representadas de frente y de perfil). 